ARTICLE

Received 19 Jan 2014 | Accepted 19 Aug 2014 | Published 9 Oct $2014 \quad$ DOl: 10.1038/ncomms6029

\title{
Epistatic interactions between neuraminidase mutations facilitated the emergence of the oseltamivir-resistant H1N1 influenza viruses
}

\author{
Susu Duan', Elena A. Govorkova1, Justin Bahl2,3, Hassan Zaraket', Tatiana Baranovich1, \\ Patrick Seiler ${ }^{1}$, Kristi Prevost ${ }^{1}$, Robert G. Webster ${ }^{1} \&$ Richard J. Webby ${ }^{1}$
}

Oseltamivir-resistant H1N1 influenza viruses carrying the $\mathrm{H} 275 \mathrm{Y}$ neuraminidase mutation predominated worldwide during the 2007-2009 seasons. Although several neuraminidase substitutions were found to be necessary to counteract the adverse effects of $\mathrm{H} 275 \mathrm{Y}$, the order and impact of evolutionary events involved remain elusive. Here we reconstruct H1N1 neuraminidase phylogeny during 1999-2009, estimate the timing and order of crucial amino acid changes and evaluate their impact on the biological outcome of the $\mathrm{H} 275 \mathrm{Y}$ mutation. Of the 12 neuraminidase substitutions that occurred during 1999-2009, 5 (chronologically, V234M, R222Q, K329E, D344N, H275Y and D354G) are necessary for maintaining full neuraminidase function in the presence of the $\mathrm{H} 275 \mathrm{Y}$ mutation by altering protein accumulation or enzyme affinity/activity. The sequential emergence and cumulative effects of these mutations clearly illustrate a role for epistasis in shaping the emergence and subsequent evolution of a drug-resistant virus population, which can be useful in understanding emergence of novel viral phenotypes of influenza.

\footnotetext{
${ }^{1}$ Department of Infectious Diseases, St Jude Children's Research Hospital, 262 Danny Thomas Place, Mail Stop 330, Memphis, Tennessee 38105, USA.

${ }^{2}$ School of Public Health, The University of Texas Health Science Center at Houston, 1200 Pressler Street, Houston, Texas 77030, USA. ${ }^{3}$ Program in Emerging Infectious Diseases, Duke-National University of Singapore Graduate Medical School, 8 College Road, Singapore 169857, Singapore.

Correspondence and requests for materials should be addressed to R.J.W. (email: Richard.Webby@sjude.org)
} 
$\mathrm{T}$ he evolutionary course of influenza A viruses is shaped by interplays among mutation, reassortment and natural selection ${ }^{1}$. Influenza A viruses, similar to all RNA viruses, have a high mutation rate ${ }^{2}$; whether a mutation can spread at a population level (epidemiologic fitness) is dependent on its impact on viral biologic fitness (replication fitness within a host and transmission fitness between hosts) ${ }^{3}$. Understanding the impact of mutations and interaction of mutations on viral fitness is, therefore, critical for a mechanistic understanding of viral phenotype emergence.

The influenza virus neuraminidase (NA) inhibitors oseltamivir and zanamivir are the options currently approved in the United States for immediate control of influenza virus infection. Their clinical use, however, provides a selection force to drive emergence of resistance within treated individuals. Before 2007, resistant viruses were detected only infrequently during NA inhibitor treatment ${ }^{4-7}$ and very rarely during surveillance ${ }^{7-9}$, suggesting that those drug-driven resistant viruses had little epidemiologic fitness. However, during the 2007-2009 influenza seasons, oseltamivir-resistant $\mathrm{H} 1 \mathrm{~N} 1$ viruses surged from $<1 \%$ to $>90 \%$ prevalence worldwide ${ }^{10-12}$. Such spread of resistance at population level was not attributed to oseltamivir use in individuals, but to global transmission of the resistant viruses carrying the NA H275Y mutation ${ }^{13,14}$, suggesting these H275Ymutant viruses had acquired advantageous epidemiologic fitness. A mechanistic understanding of such drug-independent resistance spread would give us insights to the adaptability and evolution of drug-resistant influenza viruses.

Recent studies have advanced our understanding of the biological properties of the H275Y-mutant viruses related to their different epidemiologic fitness outcomes. Genetically, the NA genes of most H275Y-mutant viruses were closely associated with the genetic $2 \mathrm{~B}$ clade (represented by A/Brisbane/59/2007 [BR07]) of H1N1 viruses but not with the other three clades (clade 1, represented by A/New Caledonia/1999 [NC99]; clade $2 \mathrm{~A}$, represented by $\mathrm{A} / \mathrm{Solomon}$ Island/23/2006 [SI06]; and clade $2 \mathrm{C})^{15-19}$. This clade-specific resistance distribution suggested a link between biologic fitness and genetic context of the H275Y mutants. Indeed, phenotypically, NC99-like H275Y mutants manifested greater biological cost relative to their respective wild-type counterparts than did BR07-like mutants, as measured by growth in cells, mice and ferrets ${ }^{20-23}$, and by their NA affinity ${ }^{15,16,19}$ and cell surface accumulation ${ }^{24}$.

Several mutations have been identified elsewhere in the NA that can counteract the adverse effects of the H275Y mutation. It has been found that the $\mathrm{D} 344 \mathrm{~N}^{16,25}, \mathrm{R} 222 \mathrm{Q}$ and $\mathrm{V} 234 \mathrm{M}^{24} \mathrm{NA}$ substitutions can counteract the reduced NA affinity and surface accumulation caused by the H275Y mutation; therefore, these mutations are 'permissive' for the H275Y mutation. Another study confirmed that changing the permissive substitutions to the non-permissive substitutions (Q222R, M234V) compromised the replication fitness of a clade $2 \mathrm{~B} \mathrm{H} 275 \mathrm{Y}$-mutant virus in vitro and in ferrets ${ }^{26}$. Although illuminating, the identification of these NA permissive mutations has not provided a full understanding of the evolutionary path and molecular process involved in the fitness changes of the H275Y-mutant viruses.

Here we reconstruct the molecular evolutionary path of the NA protein of seasonal H1N1 viruses from the NC99 to BR07 genetic lineage, during 1999-2009. We then evaluated the biological outcomes of the H275Y mutation in different NA genetic contexts at different stages of the path. We further investigate the chronological order and nature of NA mutations and their impact on the phenotypic outcome of the H275Y mutation in vitro and in vivo. These biologic fitness assessments include NA functional activity (accumulation and substrate affinity), replication in cells (plaque morphology), and viral growth and transmissibility in ferrets. We find that multiple mutations, having either permissive or compensatory epistatic interactions with the $\mathrm{H} 275 \mathrm{Y}$, sequentially alter the outcomes of the H275Y mutation in NA functionality and virus biological fitness. Our findings show biologic evidence for epistasis in which the phenotypic outcome of a mutation depends on the absence or presence of others. These results support a role for epistasis in shaping the evolution of influenza viruses, and in the emergence and spread of viral phenotype.

\section{Results}

NA protein sequence evolution from 1999 to 2009. The NA sequences of seasonal H1N1 viruses isolated during 1999-2009 showed a major genetic divergence, from the NC99 (clade 1) to BR07 (clade 2B) lineage ${ }^{15,16,19}$. We first sought to identify changes in the NA protein sequence during this lineage transition that would explain the different $\mathrm{H} 275 \mathrm{Y}$ mutation outcomes in the NC99 and BR07 lineages. Comparison of the consensus NA gene sequences revealed ten amino acid substitutions $(\mathrm{H} 45 \mathrm{~N}, \mathrm{~K} 78 \mathrm{E}$, E214G, R222Q, V234M, G249K, T287I, K329E, D344N and G354D, excluding H275Y) differentiating the lineages (Supplementary Table 1) and one substitution (D354G) differentiating wild-type and H275Y-mutant NA sequences within the BR07-like lineage. None of the substitutions resided at the NA active site (Supplementary Fig. 1).

We reconstructed the N1 NA protein's evolutionary path, focusing on the period 1999-2009, and estimated the time and order of occurrence of the amino acid substitutions by using a tip-calibrated relaxed molecular clock phylogenetic tree reconstruction method ${ }^{27}$ (Fig. 1). The NC99-like NA population (the tree trunk in Fig. 1) acquired most of the mutations in succession during 1999-2007, rather than through a single selective sweep, evolving into the BR07-like NA population in early 2007; multiple mutations were seemingly acquired at a few time points. Several intermediate NA populations (clustered away from the trunk Fig. 1) that had acquired some of the mutations co-circulated for some time but were extinguished before 2007 . The H275Y mutation occurred only sporadically in those populations, in which it ended as an NA evolutionary terminus (the tip of a branch Fig. 1). In mid-2007 (2007.485, Bayesian credible intervals, 2007.302-2007.698), soon after the BR07-like NA population was established, the $\mathrm{H} 275 \mathrm{Y}$ was fixed into the population. Only one mutation (D354G) was acquired after the H275Y, thereby completing the NA protein evolution such that oseltamivir resistance dominated the population during 2008-2009.

Different outcome of the $\mathrm{H} 275 \mathrm{Y}$ mutation in NA functionality. The NA protein sequence changes seen in our phylogenetic calculations prompted us to evaluate the possible accompanying phenotypic changes in NA functionality. To this end, we expressed the NA proteins (using equal quantities of NA-containing plasmids to partially mimic NA expression by equal quantities of infectious virus particles) and assessed their total activity and accumulation. To quantify the different NA proteins, we adapted a method for uniformly epitope-tagging recombinant proteins ${ }^{24}$. After comparing untagged, carboxyterminal-tagged and amino-terminal-tagged recombinant $\mathrm{NA}^{\mathrm{BR} / 59}$ proteins, we chose the C-terminal epitope tag for use in all NA proteins, as it did not significantly affect NA accumulation or activity (Supplementary Fig. 2). We compared lineage-representative NA proteins as well as intermediate proteins that had partial complements of the ten substitutions (Supplementary Tables 2, 3). 


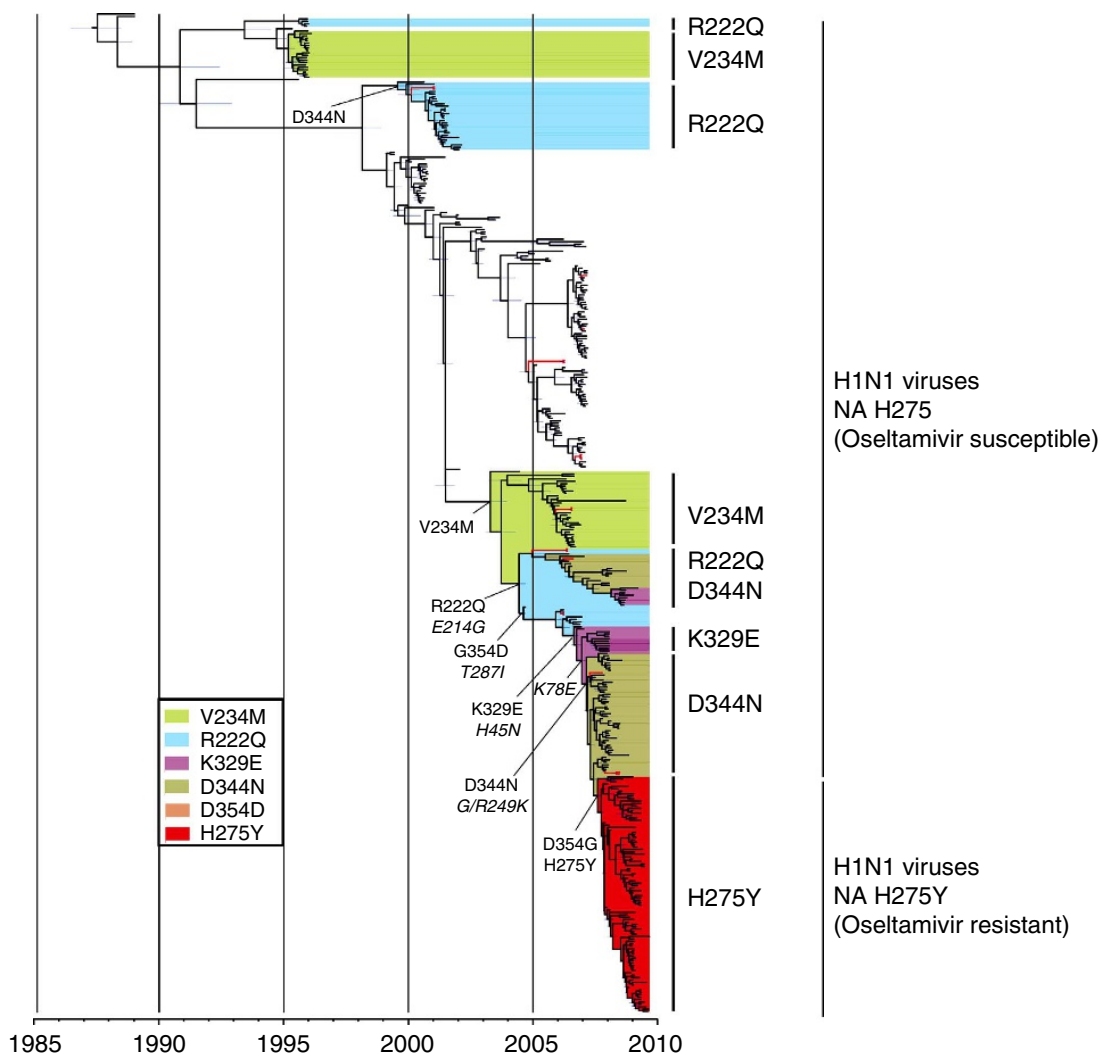

Figure 1 | Temporally structured maximum clade credibility phylogenetic tree of the NA gene of seasonal H1N1 viruses, showing the timeline of amino acid substitutions. Ancestral state reconstruction of tested amino acids is annotated on the tree backbone to indicate when specific mutations were fixed in the population. The trunk colour change indicates a $>95 \%$ posterior probability of amino acid fixation. Purple bars on tree nodes indicate the Bayesian credible intervals of ancestral divergence time estimates ( $>50 \%$ posterior probability). Isolates with $\mathrm{H} 275 \mathrm{Y}$ mutation before $\mathrm{H} 275 \mathrm{Y}$ fixation into the population are indicated with red branches.

We first evaluated NA enzyme activity (Fig. 2a). Across the two lineages, the BR07-like wild-type NA ${ }^{\mathrm{BR} / 59}$ had enzyme activity $\sim 3-4$ times that of two NC99-like wild-type proteins $\left(\mathrm{NA}^{\mathrm{GA} / 17}\right.$ and $\mathrm{NA}^{\mathrm{MEM} / 13}$ ), while the intermediate NA ${ }^{\mathrm{MS} / 03}$ (it had acquired the R222Q and D344N substitutions but not V234M yet, and therefore it had atypical intermediate genotype) had activity near that of $\mathrm{NA}^{\mathrm{BR} / 59}$. Within the NC99-like lineage, the three pairs of wild-type and H275Y-mutant NA proteins differed only at position 275; the $\mathrm{H} 275 \mathrm{Y}$-mutants $\left(\mathrm{NA}^{\mathrm{GA} / 20}\right.$ ( $\left.\mathrm{H} 275 \mathrm{Y}\right)$ and $\mathrm{NA}{ }^{\mathrm{MEM} / 13-\mathrm{H} 275 \mathrm{Y}}$ ) had activity of only $\sim 50 \%$ that of their wild-type counterparts, while the activity of the intermediate mutant $\mathrm{NA}^{\mathrm{MS} / 03}(\mathrm{H} 275 \mathrm{Y})$ was reduced least $(\sim 20 \%)$. Within the BR07-like lineage, the activity of H275Y-mutant proteins did not significantly differ from that of wild-type $\mathrm{NA}^{\mathrm{BR} / 59}$, although the two representative mutants $\left(\mathrm{NA}^{\mathrm{NJ} / 15}(\mathrm{H} 275 \mathrm{Y})\right.$ and $\mathrm{NA}^{\mathrm{NY} / 1692}$ (H275Y) had slightly higher activity and two intermediates $\left(\mathrm{NA} \mathrm{BR}^{\mathrm{BR} / 59-\mathrm{H} 275 \mathrm{Y}}\right.$ and NA ${ }^{\mathrm{NY} / 3467(\mathrm{H} 275 \mathrm{Y})}$ ) that had not acquired the D354G or D344N mutations showed slightly lower activity.

We next examined whether the observed difference in the NA activities reflected differences in their protein amount. Across the two lineages, two BR07-like wild-type proteins $\left(\mathrm{NA}^{\mathrm{BR} / 59}\right.$ and $\mathrm{NA}^{\mathrm{CA} / 27}$ ) showed higher accumulation than three NC99-like wildtype proteins ( $\mathrm{NA}^{\mathrm{GA} / 17}, \mathrm{NA}^{\mathrm{MEM} / 13}$ and $\mathrm{NA}^{\mathrm{MS} / 03}$ ) (Fig. $2 \mathrm{~b}$ and Supplementary Fig. 3a). Within the NC99-like lineage, accumulation of the three H275Y-mutant proteins was substantially lower than that of their wild-type counterparts, but accumulation of the intermediate $\mathrm{NA}^{\mathrm{MS} / 03-\mathrm{H} 275 \mathrm{Y}}$ was reduced least. Within the BR07like lineage, accumulation of the five H275Y-mutant NA proteins was similar to that of the wild-type $\mathrm{NA}^{\mathrm{BR} / 59}$. Cell surface accumulation of the NA proteins showed the same trends of change as observed in total NA accumulation (Fig. 2c).

As the protein amount differed among the NAs, we next examined each NA-specific activity by standardizing each NA's activity relative to its protein level, which reflected each NA's intrinsic conversion ability (Supplementary Fig. 3b). The differences in the standardized NA-specific activities showed similar patterns to those in the total NA activity. Across the two lineages, the standardized activity of wild-type $\mathrm{NA}^{\mathrm{BR} / 59}$ was $\sim 2-3$ times of that of the two representative NC99-like wild-type NAs (NA $\mathrm{NA}^{\mathrm{GA} / 17}$ and $\left.\mathrm{NA}^{\mathrm{MEM} / 13}\right)$. Within each lineage, all the H275Y NAs showed slightly lower standardized activity than their wild-type counterparts, except that two representative BR07-like H275Y NAs (NA ${ }^{\mathrm{NJ} / 15(\mathrm{H} 275 \mathrm{Y})}$ and NA ${ }^{\mathrm{NY} / 1692(\mathrm{H} 275 \mathrm{Y})}$ ) showed higher standardized activity than the $\mathrm{NA}^{\mathrm{BR} / 59}$. The distinct levels of NA-specific activity between the two lineages reflected that the NAs had varying intrinsic conversion ability in addition to their different expression level.

Enzyme $\mathrm{Km}$ is an intrinsic enzyme property and its value is inversely correlated with the enzyme substrate-binding affinity and enzyme conversion ability: the higher $\mathrm{Km}$ value indicates lower binding affinity and reaction rate, leading to lower activity. We next examined whether the different levels of standardized NA-specific activity reflect different $\mathrm{Km}$ values. Across the two lineages, the $\mathrm{Km}$ values of two BR07-like wild-type proteins $\left(\mathrm{NA}^{\mathrm{BR} / 59}\right.$ and NA ${ }^{\mathrm{CA} / 27}$ ) were only $\sim 25-30 \%$ those of two NC99like wild-type proteins; the intermediate $\mathrm{NA}^{\mathrm{MS} / 03}$ protein had an intermediate $\mathrm{Km}$ (Fig. 2d). Within lineages, the H275Y mutant 

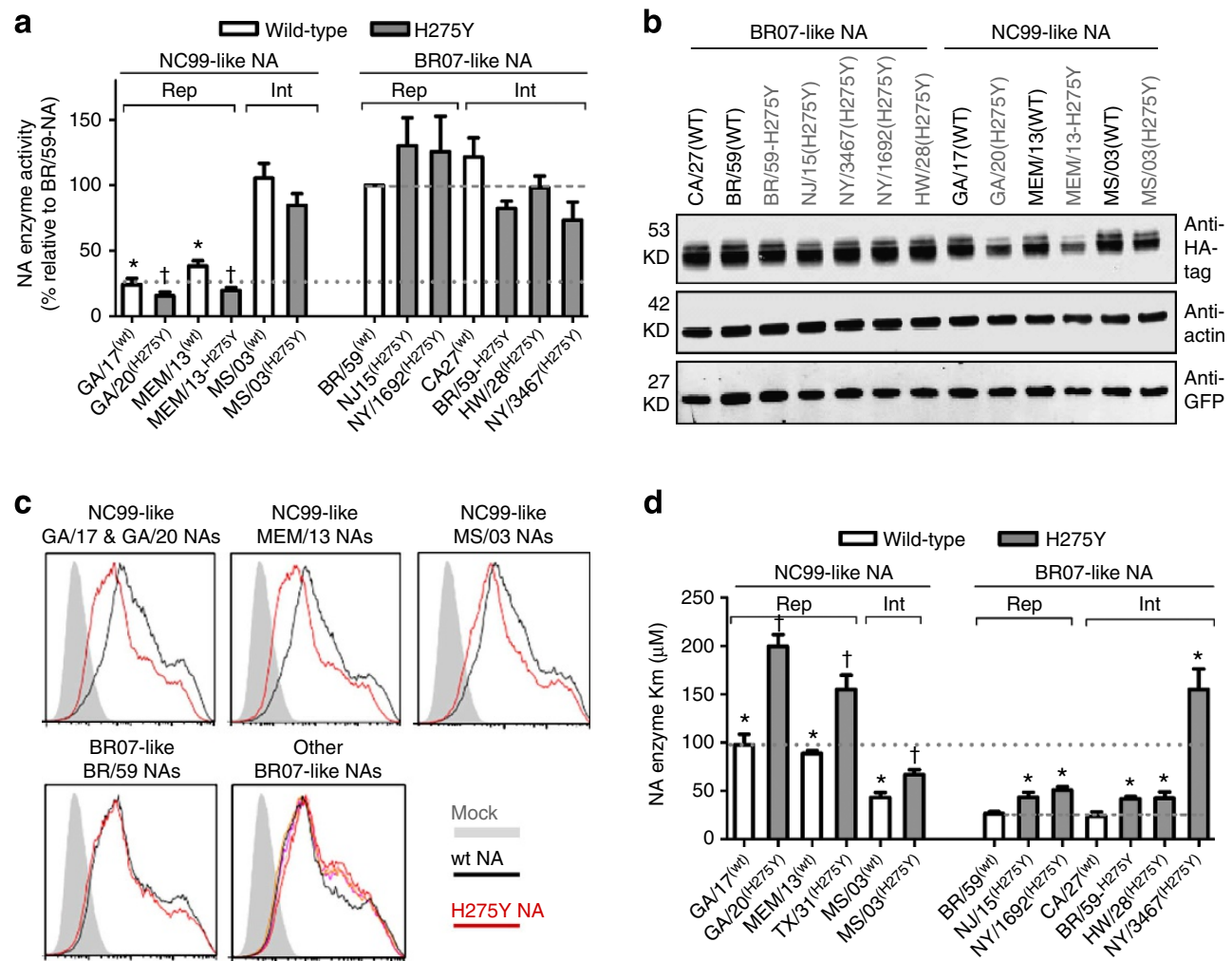

Figure 2 | NA protein phenotypes of seasonal H1N1 influenza viruses of the NC99 and BR07 lineages. (a) Neuraminidase enzyme activity of total NA proteins expressed by equal quantities $(0.5 \mu \mathrm{g})$ of the respective plasmids. Rep, representative NA protein of the indicated lineage; Int, intermediate NA protein of the indicated lineage, fully or partially conforming to the ten consensus lineage residues. The residue at the NA protein 275 position (wild-type (wt) or $\mathrm{H} 275 \mathrm{Y}$ ) is indicated in parentheses. $\mathrm{NA}-\mathrm{H} 275 \mathrm{Y}$ is shown when the $\mathrm{H} 275 \mathrm{Y}$ was introduced by mutagenesis. Data were normalized to $\mathrm{NA}{ }^{\mathrm{BRO} 7}$ protein. Dotted and dashed lines indicate the activity level of lineage-representative $N A^{G A / 17}$ and $N A^{B R / 59}$ proteins, respectively. (b) Representative western blotting showing total accumulation of NA protein variants expressed by equal quantities $(0.5 \mu \mathrm{g})$ of the respective plasmids. Black and grey indicate wt and $\mathrm{H} 275 \mathrm{Y}$-mutant NA proteins, respectively. Panels show detection by anti-HA-tag (upper), anti- $\beta$-actin (middle) and anti-GFP (lower). (c) Representative flow cytometric plots of cell surface accumulation of NA protein variants expressed by equal quantities ( $0.5 \mu \mathrm{g})$ of respective plasmids. The pairs differed only at position 275, with the exception of the last panel, the BR07-like NAs. (d) Km values of the NA proteins. The dotted and dashed lines indicate the value of lineage-representative $N A^{G A / 17}$ and $N A^{B R / 59}$, respectively. All graphs show mean \pm s.e.m. from three to five times independent experiments. ${ }^{\star} P<0.05$, two-tailed $t$-test, versus $N A^{B R / 59} ;{ }^{\dagger} P<0.05$, two-tailed $t$-test, versus its counterpart wt $N A$ at left side.

proteins had consistently higher ( $\sim 2$-fold) Km values than their wild-type counterparts; only the intermediate NA ${ }^{\mathrm{NY} / 3467}(\mathrm{H} 275 \mathrm{Y})$, which had not acquired the D344N, had an unusually high $\mathrm{Km}$ within the BR07 lineage. The lineage-associated Km levels corroborated previous reports that BR07-like viruses had greater NA affinity than the NC99-like viruses ${ }^{15,19,28}$.

Taken together, these results revealed two NA phenotypic transformations during the NC99-to-BR07 NA evolution. First, the accumulation and substrate affinity of the wild-type BR07-like NA proteins increased greatly, resulting in inherently higher functionality. Second, the outcome of the $\mathrm{H} 275 \mathrm{Y}$ mutation in net NA function differed across lineages: the H275Y-generated NA defects were severe in the NC99-like NA proteins but minimal or absent in the BR07-like NA proteins. These results indicate that certain mutations acquired by the BR07-like NA proteins contributed to the observed NA phenotypic transformations.

Different outcome of NA H275Y in virus transmissibility. The observed NA phenotypic transformations during NC99-BR07 NA evolution prompted us to assess the transmissibility of representative viruses isolated at different stages of the evolution path, an essential factor for virus spread. To this end, we chose a ferret model to recapitulate virus human transmission. Although so far it is recognized as the best model to recapitulate human transmission of influenza virus, ferret model has limitations such as outbred model and random factors in sneezing activity and so on; hence, we chose to assess multiple wild-type and H275Y-mutant viruses of each lineages, looking for common observations for each lineage. We assessed the growth and transmissibility of selected viruses via direct contact and respiratory droplets in influenza-naive ferrets. Transmission was indicated by nasal virus shedding and seroconversion (Fig. 3 and Supplementary Table 4).

In the NC99 lineage, both the wild-type (MEM/13/06) and $\mathrm{H} 275 \mathrm{Y}$-mutant (GA/20/06 and MS/03/02) viruses caused productive infection in three of three inoculated donor ferrets, but the two $\mathrm{H} 275 \mathrm{Y}$ mutants were shed at much lower titres on day 1 post inoculation (p.i., $\sim 3$ and $1.5 \log _{10} \mathrm{TCID}_{50}$ lower, respectively) (Fig. 3a). At day 1 post contact (p.c.), only the wild-type virus had been transmitted to three of three recipients by direct contact, and neither $\mathrm{H} 275 \mathrm{Y}$ mutant had been transmitted to all recipients and their titres were $\sim 3 \log _{10} \mathrm{TCID}_{50}$ lower (Fig. $3 \mathrm{~b}$ ). The wild-type virus was transmitted via respiratory droplets to two of three ferrets at days 3 and 5 p.c., while both the H275Y mutants were transmitted to only one of three ferrets at days 7 and 9 p.c. (Fig. 3c). Therefore, the transmission of the two NC99-like H275Y mutants was commonly slower and less 


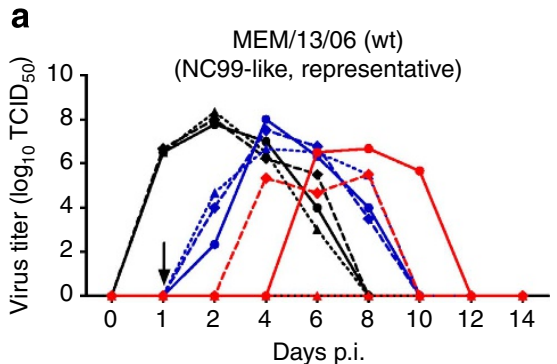

BR/59/07 (wt)

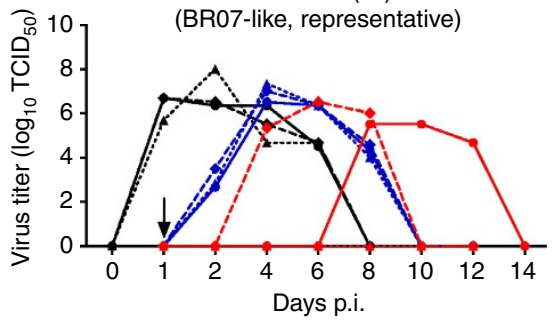

NY/3467/09 (H275Y)

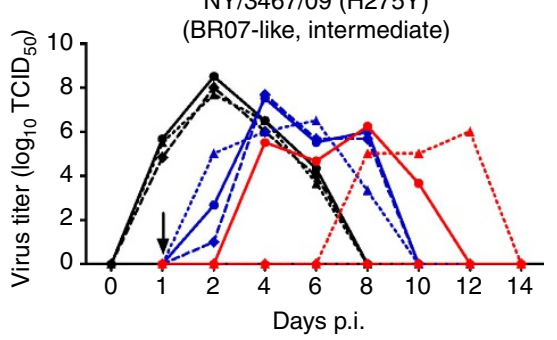

b

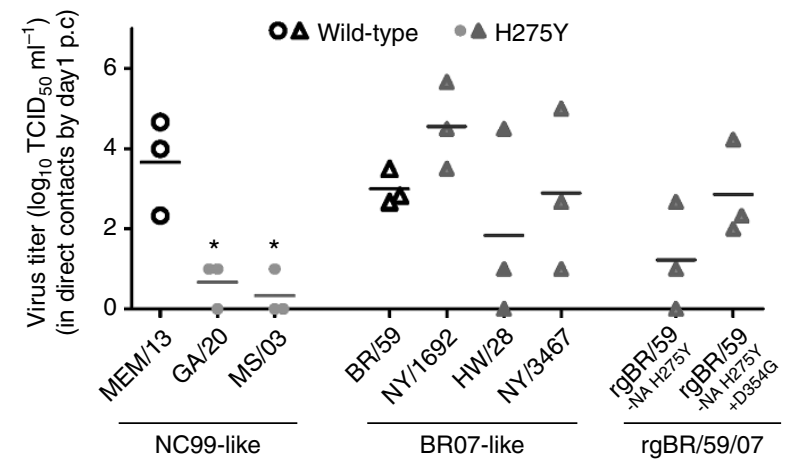

GA/20/06 (H275Y)

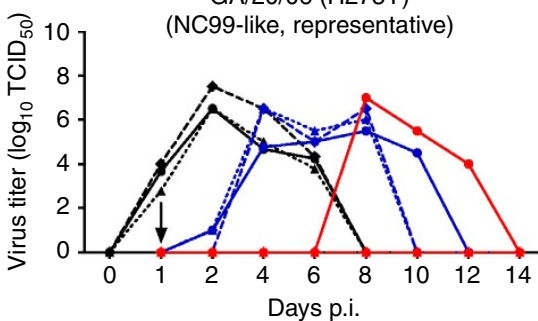

$\mathrm{NY} / 1692 / 09$ (H275Y)

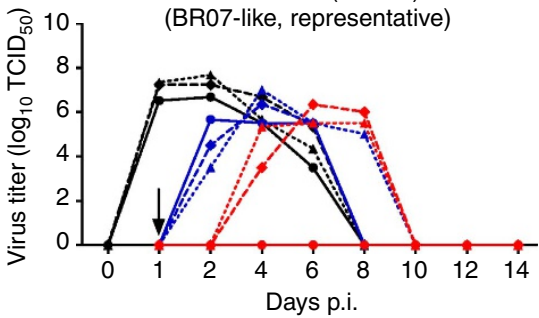

$\mathrm{rgBR} / 59 / 07-\mathrm{NA}^{\mathrm{H} 275 \mathrm{Y}}$

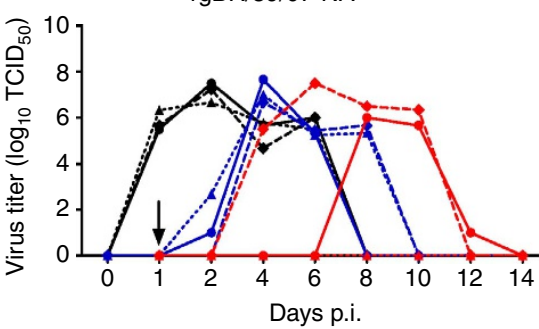

MS/03/02 (H275Y)

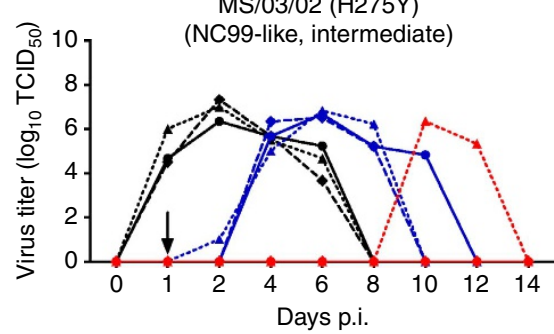

$\mathrm{HW} / 28 / 07$ (H275Y)

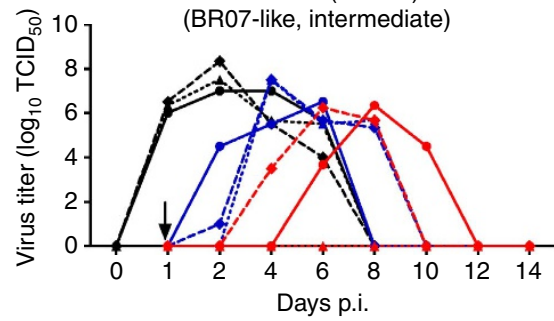

$\mathrm{rgBR} / 59 / 07-N A^{\mathrm{H} 275 \mathrm{Y}+\mathrm{D} 354 \mathrm{G}}$

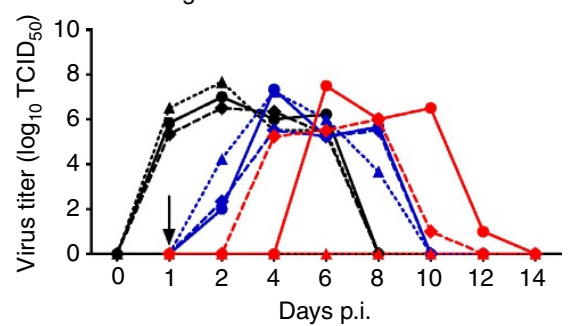

C

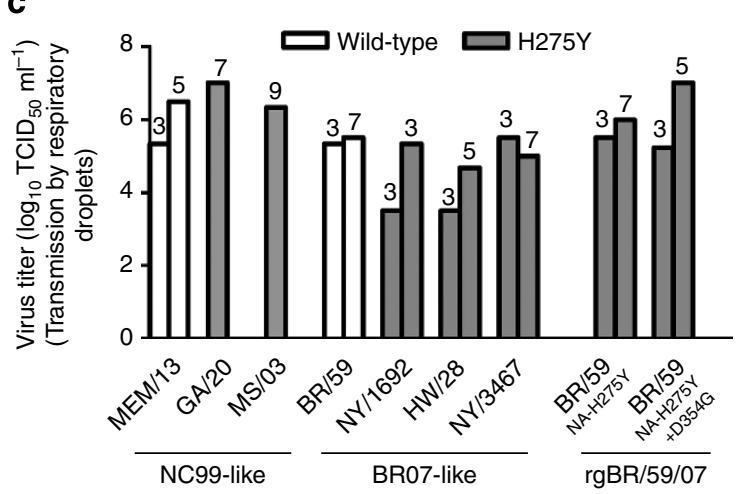

Figure 3 | Transmissibility of seasonal H1N1 influenza viruses of the NC99 and BR07 lineages in ferrets. (a) Virus titres in nasal wash samples from individual donor ferrets (black), direct-contact (DC) ferrets (blue) and respiratory-droplet (RD) ferrets (red). Arrows indicate the day (day 1 p.i for donors) when recipient ferrets were housed with donor ferrets. (b) Virus titres in DC ferret nasal wash samples at day 1 post contact. Each dot represents an individual ferret. ${ }^{*} P<0.05$, two-tailed $t$-test, versus MEM/13. (c) Virus titres in RD ferret nasal wash samples on the first day of detection (the day post contact), which is indicated above each column.

efficient than the NC99-like wild-type virus, suggesting that the transmissibility of the NC99-like H275Y mutants was impaired, consistent with their severe NA defects observed.

In the BR07 lineage, the wild-type (BR/59/07) and three H275Y-mutant viruses (HW/28/07, NY/3467/09 and NY/1692/ 09 ) caused productive infection in all inoculated donors (three of three). Virus shedding between wild-type and H275Y-mutant virus only differed in the intermediate NY/3467/09 virus $(\sim 1.5$ $\log _{10}$ TCID $_{50}$ lower in the mutant virus at day 1 p.i.) (Fig. $3 a$ ). Each virus had been transmitted to three of three recipients by direct contact at day 1 p.c. (Fig. $3 b$ ), showing similar transmission kinetics, although the intermediate $\mathrm{HW} / 28 / 07$ virus was transmitted later to one recipient. Each virus was transmitted to two of three recipients via respiratory droplets, with similar kinetics (Fig. 3c), except that the representative H275Y-mutant NY/1692/ 09 virus was transmitted earlier (day 3 p.c.) than the wild-type BR/59/07 (day 7 p.c.) to one recipient. Therefore, the transmission efficiency of the three BR07-like H275Y mutants was commonly similar to the BR07-like wild-type virus, showing that the transmissibility of BR07-like $\mathrm{H} 275 \mathrm{Y}$ mutant viruses is minimally impaired or not impaired, consistent with their minimal or absent NA defects observed.

We next generated two $\mathrm{H} 275 \mathrm{Y}$ mutant reverse-genetics (rg)

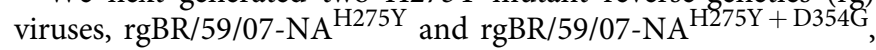
to represent the evolutionary acquisition of the $\mathrm{H} 275 \mathrm{Y}$ and D354G mutations within the BR07 lineage. Both H275Y mutants 
productively infected three of three inoculated ferrets (Fig. 3a). They were transmitted to three of three recipients via direct contact and to two of three via respiratory droplets, but with different kinetics. At day 1 p.c., only the $\mathrm{NA}^{\mathrm{H} 275 \mathrm{Y}}$ virus had not been transmitted to all direct-contact ferrets (were transmitted only two of three), showing slightly slower transmission than that of the wild-type and $\mathrm{NA} 275 \mathrm{Y}+\mathrm{D} 354 \mathrm{G}$ viruses (Fig. 3b); the $\mathrm{NA}^{\mathrm{H} 275 \mathrm{Y}+\mathrm{D} 354 \mathrm{G}}$ virus was transmitted to two of three recipients via respiratory droplets at days 3 and 5 p.c., showing slightly faster transmission than did the wild-type and $\mathrm{NA}^{\mathrm{H} 275 \mathrm{Y}}$ viruses (transmission at days 3 and 7 p.c.) (Fig. 3c). These results were consistent with the observations from the three BR07-like $\mathrm{H} 275 \mathrm{Y}$-mutant viruses and further confirmed that the H275Y mutation minimally reduced the transmissibility of the BR/59/07 virus and suggested that addition of D354G restored the transmissibility of the H275Y-mutant virus to the wild-type level. Another report ${ }^{29}$ found that D354G not only increased the transmissibility of a resistant virus in guinea pigs but also to a level higher than that of the wild-type virus, suggesting that the extent of D354G increasing resistant virus transmissibility may depend on other viral protein context.

In summary, the growth and transmissibility of NC99-like and BR07-like wild-type viruses was indistinguishable despite their different NA phenotypes. However, the growth and transmissibility outcome of the $\mathrm{H} 275 \mathrm{Y}$-mutant variants differed greatly between the two lineages, as did the extent of H275Y-generated NA defects, suggesting that the NA defects was directly correlated with virus transmissibility.
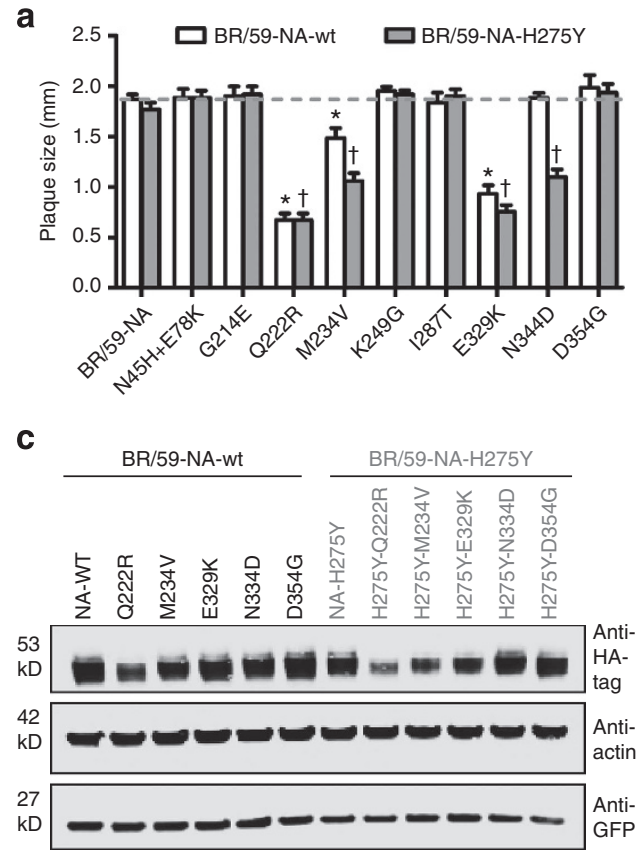

Mutation interactions alter phenotypic outcome of NA H275Y. We next sought to identify which of the 11 amino acid substitutions that occurred during the NC99-BR07 NA evolution account for the observed NA phenotypic transformations. To this end, we examined the impact of each individual mutation on NA functionality with or without the $\mathrm{H} 275 \mathrm{Y}$ mutation.

We first adopted a strategy using plaque size to evaluate NAmediated virus release during the replication cycle. A plaque is formed from a single virus particle via multiple cycles of replication, and release of the progeny viruses at each cycle is mediated by NA functionality. Thus, NA mutation that could alter NA activity sufficiently would directly affect the speed of virus release and consequently determine the plaque size. We first validated the feasibility of this strategy by confirming that plaque size paralleled NA enzyme activity in two pairs of $\mathrm{rg}$ viruses, a BR07-like pair (NA ${ }^{\mathrm{BR} / 59}$ and NA ${ }^{\mathrm{BR} / 59-\mathrm{H} 275 \mathrm{Y}}$ ) and an NC99-like pair (NA ${ }^{\mathrm{GA} / 17}$ and $\mathrm{NA}^{\mathrm{GA} / 20}(\mathrm{H} 275 \mathrm{Y})$ ) (each pair differs only at position 275; Supplementary Fig. 4a,b). We next generated rgBR/ $59 / 07$ viruses whose NA proteins carried the respective substitutions N45H + E78K, G214E, Q222R, M234V, K249G, I287T, E329K, N344D and D354G (representing a change from BR07like to NC99-like), in the presence and absence of H275Y. Four substitutions (Q222R, M234V, E329K and N344D) in NA $\mathrm{NR}^{\mathrm{BR} / 59}$ significantly reduced plaque size, with and/or without the H275Y (Fig. 4a and Supplementary Fig. 5a). These four positions and the final substitution site (354) were selected for further evaluation; the remaining five substitutions were unlikely to reduce virus growth appreciably and were not further evaluated.

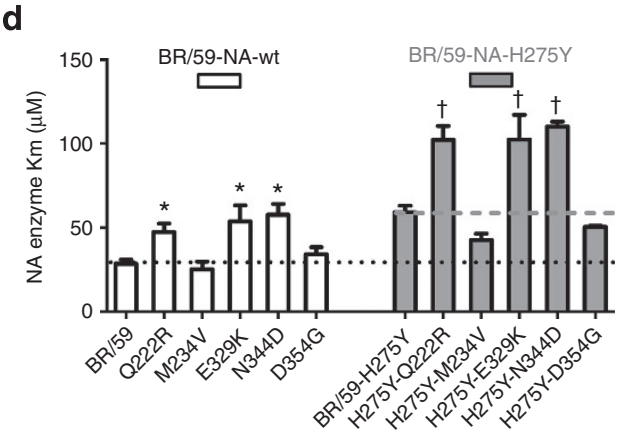

Figure 4 | Plaque size, NA activity, NA accumulation and substrate affinity of the BR/59/07 NA proteins with different amino acid substitutions. (a) Plaque size of viruses carrying ten different NA amino acid substitutions, in the absence (white) or presence (grey) of the H275Y mutation. The ten amino acid residues were replaced with the corresponding NC99-like consensus residues. $(\mathrm{N} 45 \mathrm{H}+\mathrm{E} 78 \mathrm{~K}$ were substituted together, as both reside in the stalk region.) Data represent mean \pm s.e.m. diameter of $\sim 10$ randomly selected plaques. Dashed line indicates mean plaque diameter of wild-type $N A^{B R / 59}$. (b) Enzyme activity of total $N A^{B R 07}$ and $N A^{B R 07-H 275 Y}$ variant proteins with five different amino acid substitutions, expressed by equal quantities $(0.5 \mu \mathrm{g})$ of the respective plasmids. Dotted and dashed lines indicate mean activity of $N A^{B R / 59}$ and $N A^{B R / 59-H 275 Y}$, respectively. (c) Representative western blotting showing total accumulation of protein variants with substitutions; the variants were expressed by equal quantities ( $0.5 \mu \mathrm{g})$ of the respective plasmids. Black and grey indicate wt and H275Y-mutant NA, respectively. Panels show detection by anti-HA-tag (upper), anti- $\beta$-actin (centre) and anti-GFP (lower). (d) NA Km values of rgBR/59/07 viruses carrying the respective NA amino acid substitutions in the absence and presence of the $\mathrm{H} 275 \mathrm{Y}$ mutation. Dotted and dashed lines indicate the values of $N A^{B R / 59}$ and $N A^{B R / 59-H 275 Y}$, respectively. All graphs represent mean \pm s.e.m. of three to five times independent experiments. ${ }^{\star} P<0.05$, two-tailed $t$-test, versus $N A^{B R / 59} ; \uparrow<0.05$, two-tailed $t$-test, versus $N A^{B R / 59-H 275 Y}$. 
The four substitutions (Q222R, M234V, E329K and N344D) variably reduced enzyme activity in $\mathrm{NA}^{\mathrm{BR} / 59}$ or $\mathrm{NA}^{\mathrm{BR} / 59-\mathrm{H} 275 \mathrm{Y}}$ (Fig. 4b), consistent with the reduced plaque size observed. Conversely, although not notably increasing plaque size, the D354G substitution significantly increased enzyme activity in both $\mathrm{NA}^{\mathrm{BR} / 59}$ and $\mathrm{NA}^{\mathrm{BR} / 59-\mathrm{H} 275 \mathrm{Y}}$; it increased the enzyme activity $\mathrm{NA}^{\mathrm{BR} / 59-\mathrm{H} 275 \mathrm{Y}}$ to a level equivalent or slightly higher than that of $\mathrm{NA}^{\mathrm{BR} / 59}$. Two substitutions (Q222R and M234V) in both $\mathrm{NA}^{\mathrm{BR} / 59}$ and $\mathrm{NA}^{\mathrm{BR} / 59-\mathrm{H} 275 \mathrm{Y}}$ greatly reduced the NA protein accumulation (Fig. 4c and Supplementary Fig. 5b) and the level of accumulation resulted by each mutation with $\mathrm{H} 275 \mathrm{Y}$ was much lower than that by each mutation alone (such as H275Y-Q222R versus Q222R alone). Three substitutions (Q222R, E329K and $\mathrm{N} 344 \mathrm{D})$ in both $\mathrm{NA}^{\mathrm{BR} / 59}$ and $\mathrm{NA}^{\mathrm{BR} / 59-\mathrm{H} 275 \mathrm{Y}}$ significantly increased the $\mathrm{Km}$ value $\sim 2$-fold compared with $\mathrm{Km}$ of $\mathrm{NA}^{\mathrm{BR} / 59}$ and $\mathrm{NA} \mathrm{BR}^{\mathrm{BR} / 59-\mathrm{H} 275 \mathrm{Y}}$, respectively (Fig. $4 \mathrm{~d}$ ), and the $\mathrm{Km}$ values resulted by each mutation with $\mathrm{H} 275 \mathrm{Y}$ was much higher than that by each mutation alone (such as H275Y-Q222R versus Q222R alone). The three $\mathrm{Km}$-changing mutations differently reduced NA-specific activity with Q222R causing the biggest reduction (Supplementary Fig. 5c). The D354G substitution had no appreciable effect on protein accumulation or $\mathrm{Km}$ values but significantly increased the NA-specific activity (Supplementary Fig. $5 \mathrm{c}$ ). The 354 position resides at the NA surface but faces toward the virion's membrane (Supplementary Fig. 1) and therefore is structurally unlikely to affect substrate interaction directly. Thus, D354G increased enzyme conversion ability by unidentified mechanisms other than Km level. In contrast, the three affinity-changing mutations (Q222R, E329K and N344D) are located at the NA surface and face away from the virion's membrane and tetramer interface (Supplementary Fig. 1), structurally allowing substrate interaction.

Together, our results identified two classes of mutation interaction in $\mathrm{NA}^{\mathrm{BR} / 59}$ that sequentially altered the outcome of the H275Y mutation in net NA function. First, acquisition of R222Q, V234M, K329E and D344N mutations by NA $\mathrm{NR}^{\mathrm{B} / 59}$ each increased NA activity and thus minimized subsequent H275Ygenerated defects. Second, acquisition of the D354G mutation by $\mathrm{NA}^{\mathrm{BR} / 59-\mathrm{H} 275 \mathrm{Y}}$ increased NA activity to wild-type protein levels, resulting in unaltered net NA functionality. Thus, the higher levels of enzyme activity (Fig. 2a and Supplementary Fig. 3b) of $\mathrm{NA}^{\mathrm{NJ} / 15}(\mathrm{H} 275 \mathrm{Y})$ and $\mathrm{NA}^{\mathrm{NY} / 1692(\mathrm{H} 275 \mathrm{Y})}$ reflected their further acquisition of the D354G after the H275Y addition and demonstrated the role of D354G in increasing H275Y NA activity.

\section{Reconstruction of NC99-BR07 NA phenotypic evolution in vitro.} We next tested whether the molecular determinants identified above were sufficient to explain the NA phenotypic transformations that accompanied the NC99-BR07 transition. The V234M, $\mathrm{R} 222 \mathrm{Q}, \mathrm{K} 329 \mathrm{E}$ and D344N mutations (representing a change from NC99-like to BR07-like) were introduced into the NA ${ }^{\mathrm{GA} / 17}$ and NA ${ }^{\mathrm{GA} / 20}$ (H275Y) (already possessing the D354G mutation) NC99-like proteins, which differed only at position 275. All substitutions, except D344N, significantly increased the functional activity of $\mathrm{NA}^{\mathrm{GA} / 17}$ and, to a lesser extent, of $\mathrm{NA}^{\mathrm{GA} / 20(\mathrm{H} 275 \mathrm{Y})}$ (Supplementary Fig. 6a). Enzyme activity paralleled the plaque size of the mutant viruses (Supplementary Fig. 6b). In NA $\mathrm{NA}^{\mathrm{G} / 17}$, two substitutions (R222Q and V234M) greatly increased NA protein accumulation (Fig. 5a) and three (R222Q, K329E and D344N) variably reduced the Km value (Fig. 5b); all of these changes occurred to a lesser extent in $\mathrm{NA}^{\mathrm{GA} / 20(\mathrm{H} 275 \mathrm{Y})}$. These findings confirmed that these four substitutions play a role in increasing overall NA function and in reducing the $\mathrm{H} 275 \mathrm{Y}$-generated defects, although no single substitution could alone fully transform the NA phenotype and fully offset the H275Y-generated defects. Thus, the intermediate level of NA accumulation observed in $\mathrm{NA}^{\mathrm{MS} / 03}, \mathrm{NA}^{\mathrm{MS} / 03}$ (H275Y) (which had acquired R222Q and D344N) and unusually high Km value in $\mathrm{NA}^{\mathrm{NY} / 3467(\mathrm{H} 275 \mathrm{Y})}$ (which had not acquire the D344N) (Fig. 2) can be explained by partial acquisition of these phenotypic determinants.

We then evaluated whether sequential addition of all four phenotypic determinants were sufficient to fully reconstruct the BR07-like NA phenotype. The four substitutions were consecutively added to the NC99-like $\mathrm{NA}^{\mathrm{GA} / 17}$ and NA ${ }^{\mathrm{GA} / 20}$ (H275Y) proteins in the order indicated by the phylogenetic reconstruction of ancestral states (V234M-R222Q-K329E-D344N or V234MR222Q-D344N-K329E) (Fig. 1). The sequential addition of the four substitutions progressively increased the functional activity of NA ${ }^{\mathrm{GA} / 17}$ and NA ${ }^{\mathrm{GA} / 20(\mathrm{H} 275 \mathrm{Y})}$ to a final level equivalent to that

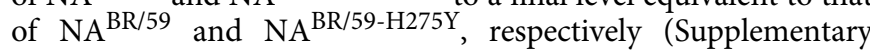
Fig. 7a). The increased NA activity closely paralleled increased plaque size (Supplementary Fig. 7b). Addition of V234M and R222Q, but not the two subsequent mutations, to $\mathrm{NA}^{\mathrm{GA} / 17}$ and $\mathrm{NA}^{\mathrm{GA} / 20(\mathrm{H} 275 \mathrm{Y})}$ increased NA protein accumulation to a level equivalent to that of $\mathrm{NA}^{\mathrm{BR} / 59}$ and $\mathrm{NA}^{\mathrm{BR} / 59-\mathrm{H} 275 \mathrm{Y}}$, respectively (Fig. 5c). Addition of V234M did not appreciably reduce $\mathrm{Km}$, but subsequent addition of R222Q, K329E and D344N progressively reduced the $\mathrm{Km}$ values of $\mathrm{NA}^{\mathrm{GA} / 17}$ and $\mathrm{NA}^{\mathrm{GA} / 20(\mathrm{H} 275 \mathrm{Y})}$ (Fig. 5d) to that of $\mathrm{NA}^{\mathrm{BR} / 59}$ and $\mathrm{NA}^{\mathrm{BR} / 59-\mathrm{H} 275 \mathrm{Y}}$, respectively.

In summary, sequential addition of the four identified molecular determinants into the two NC99-like NA proteins (already possessing the D354G mutation) fully reconstructed the BR07-like NA phenotype. The impact of the interactions of the V234M and R222Q with the H275Y on total NA accumulation corroborated and expanded previous findings about surface NA accumulation ${ }^{24}$. The two subsequent substitutions, K329E and D344N, increased NA affinity and further reduced H275Y-generated NA functional losses.

The outcome of the H275Y mutation in other N1-subtype NA. As the NA H275Y mutation is associated with oseltamivir resistance mainly in the N1 subtype, we evaluated the functional outcomes of the $\mathrm{H} 275 \mathrm{Y}$ mutation in other N1 proteins, including those of two human 2009 pandemic H1N1 (pdmH1N1) (NACA) 04 and NA ${ }^{\mathrm{DM} / 524}$ ) (Fig. 6a,b) and two human H5N1 (NA ${ }^{\mathrm{VN} / 1203}$ and $\mathrm{NA}^{\mathrm{HK} / 213}$ ) viruses (Fig. $6 \mathrm{c}, \mathrm{d}$ ). The $\mathrm{H} 275 \mathrm{Y}$ mutation caused loss of NA activity by $45-70 \%$ in these four NA proteins and greatly diminished their surface accumulation (Fig. 6). The extent of H275Y-generated defects observed in these four N1 proteins showed that that the $\mathrm{H} 275 \mathrm{Y}$ mutation remained deleterious for NA functionality in these NA genetic contexts, suggesting that additional mutations would be required to restore NA functionality for these four viruses to carry $\mathrm{H} 275 \mathrm{Y}$ mutation to spread to any degree. These results demonstrate evaluation of the biology cost by the H275Y mutation at protein level can be an informative analytic tool for assessing other emerging resistant viruses in other future studies.

\section{Discussion}

The findings presented in this study detail the molecular mechanisms and temporal process by which the biologic fitness of oseltamtivir-resistant $\mathrm{H} 1 \mathrm{~N} 1$ viruses was altered by epistatic interactions between successive NA mutations. We discovered that the NA molecular changes (in the temporal order V234MR222Q-K329E-D344N-H275Y-D354G), which occurred during NA genetic evolution during 1999 2009 gradually reduced and finally mitigated $\mathrm{H} 275 \mathrm{Y}$-generated defects on NA functionality. The genetic context-dependent fitness outcome of the H275Ymutant viruses is characteristic of epistasis effects. Therefore, the 

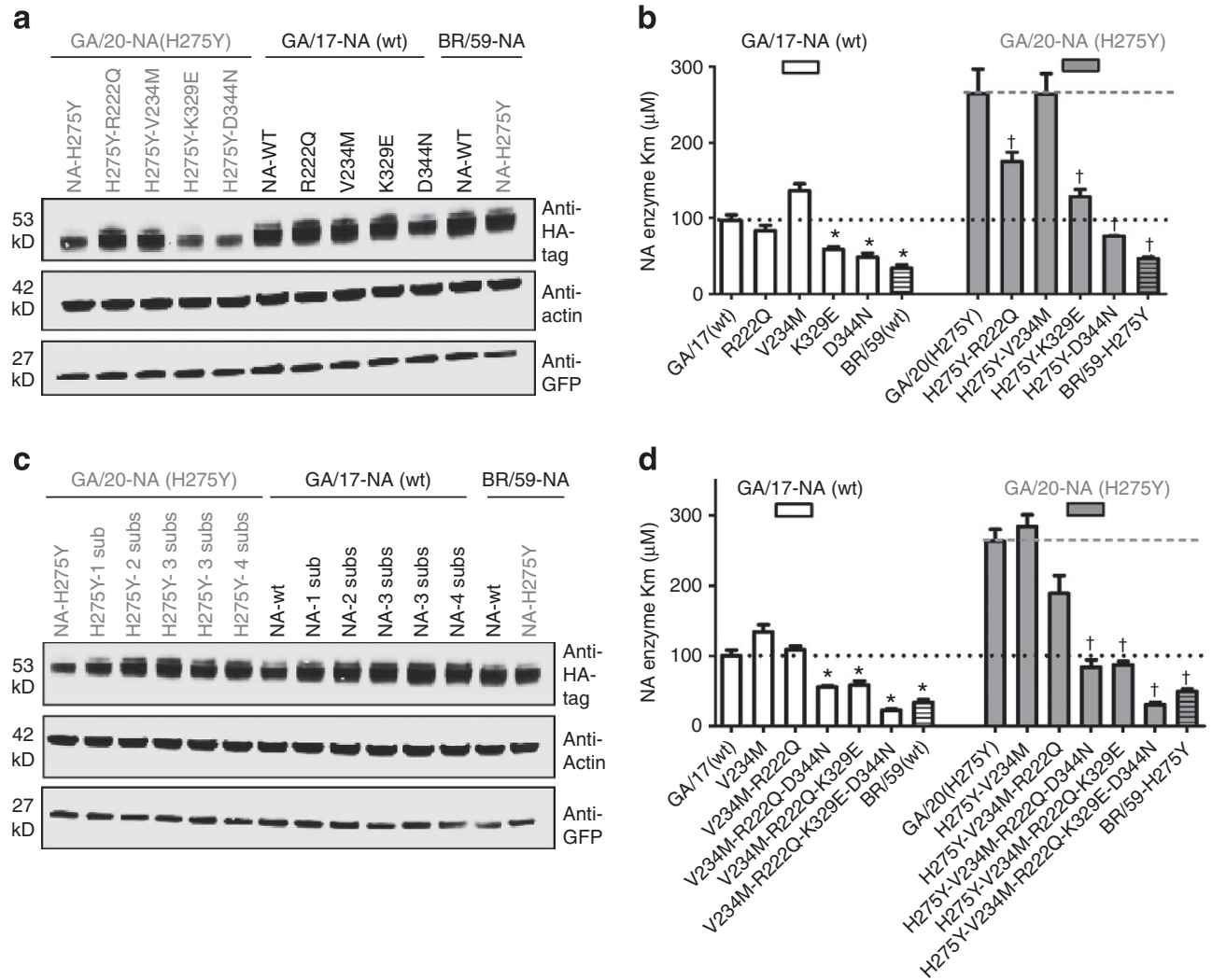

Figure 5 | Total protein accumulation and Km values of the NC99-like NA proteins with different amino acid substitutions. (a) Representative western blotting showing total accumulation of the NC99-like NA proteins (NA ${ }^{G A / 17}$ and $N A^{G A / 20}(H 275 Y)$ ) with the indicated single substitutions; the variant NAs were expressed by equal quantities $(0.5 \mu \mathrm{g})$ of the respective plasmids. Black and grey indicate wt and H275Y-mutant NA proteins, respectively. (b) NA Km values of rgBR/59/07 viruses carrying $N A^{G A / 17}$ or $N A^{G A / 20 ~(H 275 Y) ~ w i t h ~ t h e ~ i n d i c a t e d ~ s i n g l e ~ s u b s t i t u t i o n s . ~ D o t t e d ~ a n d ~ d a s h e d ~}$ lines indicate $\mathrm{Km}$ values of $N A^{\mathrm{GA} / 17}$ and $N A^{\mathrm{GA} / 20}\left(\mathrm{H} 275 \mathrm{Y}\right.$ ), respectively. (c) Representative western blotting showing total accumulation of $N A^{\mathrm{GA} / 17}$ and $N A^{G A / 20(H 275 Y)}$ proteins with sequentially added substitutions (sub), the order is the same in next panel; NAs were expressed by equal quantities $(0.5 \mu \mathrm{g})$ of respective plasmids. (d) NA Km values of rgBR/59/07 viruses carrying the NA ${ }^{\mathrm{GA} / 17}$ and NA ${ }^{\mathrm{GA} / 20}$ (H275Y) with sequentially added substitutions. Dotted and dashed lines indicate $\mathrm{Km}$ values of $N A^{\mathrm{GA} / 17}$ and $N A^{\mathrm{GA} / 20(\mathrm{H} 275 \mathrm{Y})}$, respectively. All graphs show mean \pm s.e.m. of three to five times independent experiments. ${ }^{\star} P<0.05$, two-tailed $t$-test, versus $N A G A / 17 ;{ }^{\dagger} P<0.05$, two-tailed $t$-test, versus $N A{ }^{G A / 20}$ (H275Y).

sequential and cumulative epistatic interactions in NA contributed substantially to the evolutionary course of the $\mathrm{H} 275 \mathrm{Y}$ mutation-containing $\mathrm{H} 1 \mathrm{~N} 1$ viruses.

Epistatic interactions occurs when the phenotypic outcome of a mutation is conditional to the presence or absence of other mutations in the genome $\mathrm{e}^{30}$ and it can have either positive (alleviating) or negative (aggravating) effects ${ }^{30}$. Epistasis in influenza A viruses has been estimated by modelling sequence evolution of human $\mathrm{H} 3 \mathrm{~N} 2$ and $\mathrm{H} 1 \mathrm{~N} 1$ viruses $^{31-33}$, and was suggested to be prevalent in haemagglutinin (HA) and NA proteins $^{31}$. There have, however, been few biological observations of epistatic interactions at the protein or virus phenotypic level. In one example, two advantageous immune-escape Nucleoprotein mutations that would have otherwise been destabilizing were acquired through interaction with other stabilizing mutations ${ }^{34}$. Our findings provide direct biological evidence of epistatic interactions in determining phenotypic outcome of a drug-resistant mutation during NA evolution. The interaction sites were concordant with a previous statistical analysis based on NA sequence alone $^{31}$, supporting a role for epistasis in shaping influenza virus evolution.

In the context of current knowledge, our results suggest a fourstage scenario of molecular evolution of the NA protein in $\mathrm{H} 1 \mathrm{~N} 1$ viruses during 1999-2009: (1) during 1999-2006, incidental introduction of the NA $\mathrm{H} 275 \mathrm{Y}$ mutation into the predominant circulating NC99-like viruses severely impaired NA functionality and, consequently, virus fitness and ability to spread. These viruses became extinct. (2) Meanwhile, during 1999-2006, the NC99-like viruses gradually evolved under host pressures, including immunity. The NA protein sequentially acquired 12 substitutions, of which R222Q, K329E, G249K and D344N have been shown to cause NA antigenic drift $^{35}$, while V234M, R222Q, K329E and D344N greatly enhanced NA accumulation and/or substrate affinity. (3) In 2007, a new BR07 lineage, which had undergone $\mathrm{HA}$ and NA antigenic drift, emerged and became prevalent. The introduction of the NA $\mathrm{H} 275 \mathrm{Y}$ mutation into BR07-like viruses minimally reduced NA function due to its increased surface accumulation and/or substrate affinity as compared with the NC09-like NA. (4) After the H275Y substitution was acquired in mid-2007, final addition of the NA D354G fully compensated for the remaining H275Y-generated functional defects. Therefore, these BR07-like, oseltamivirresistant viruses had no net loss of NA function, had biological fitness equal at least to that of the BR07-like wild-type viruses and spread readily during the 2008-2009 influenza season.

Our findings show the presence of two types of epistatic interactions that collectively altered the H275Y phenotype. Four permissive epistatic mutations (V234M, R222Q, K329E and $\mathrm{D} 344 \mathrm{~N}$ ) were selected before addition of H275Y, increasing overall NA functionality fist and providing a permissive context 
a

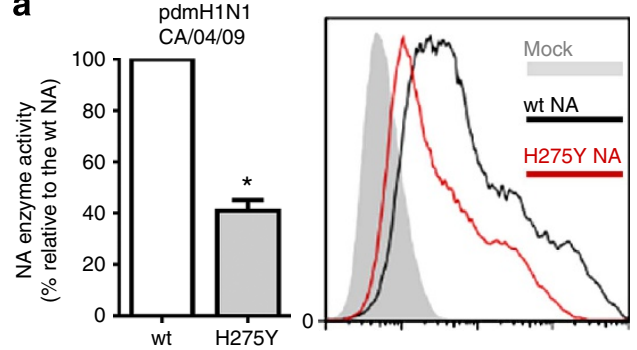

C

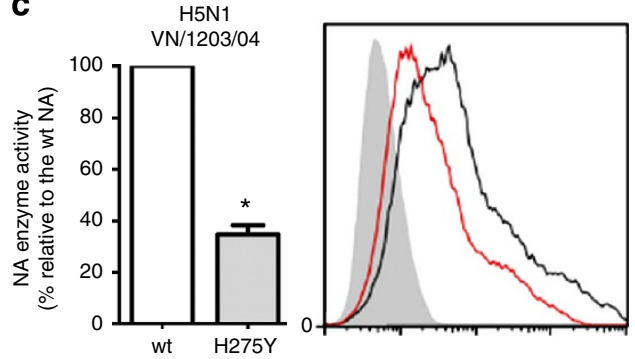

b

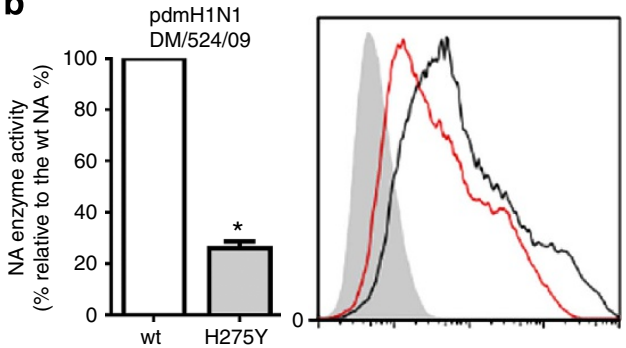

d

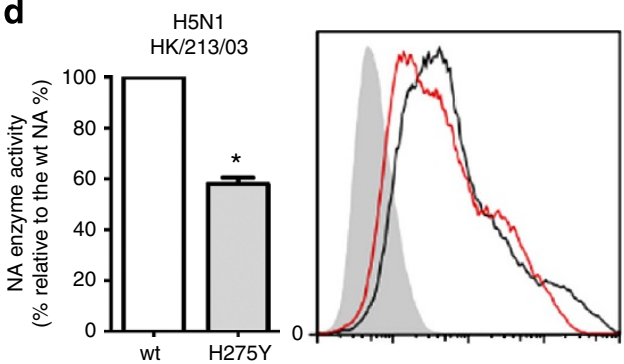

Figure 6 | Defects in enzyme activity and protein accumulation caused by the H275Y mutation in other N1-subtype NA proteins. Each panel shows a pair of NA protein variants differing only in the absence or presence of the H275Y mutation, including two pairs of pdmH1N1 NA proteins $(\mathbf{a}, \mathbf{b})$ and two pairs of hpH5N1 NA proteins $(\mathbf{c}, \mathbf{d})$. Enzyme activity of total accumulated NA protein is shown at left in each panel. Representative flow cytometry plots showing surface accumulation are at right. NA proteins were expressed by equal quantities $(0.5 \mu \mathrm{g})$ of respective plasmids. Data are the mean \pm s.e.m. of at four determinations. ${ }^{\star} P<0.05$, two-tailed $t$-test, versus its counterpart wild-type NA.

for potential function-decreasing mutation. The D354G mutation, which was added to the BR07-like NA population immediately after $\mathrm{H} 275 \mathrm{Y}$ acquisition, was very likely to be selected due to its ability to mitigate remaining H275Y-associated functional defects in a typical epistatic compensatory manner. The combined phenotypic effects of both the permissive and compensatory mutations were required to maintain the net NA function of the H275Y-mutant protein.

The emergence of the V234M and R222Q substitutions before 1999 suggests that the selection forces for these substitutions had existed and was not drug pressure. The extensive overlap of the four permissive NA mutations (V234M, R222Q, K329E and $\mathrm{D} 344 \mathrm{~N}$ ) and the four reported antigenic-drift NA mutations (R222Q, G249K, K329E and D344N) ${ }^{35}$ suggests that host antiNA immunity may have been the primary driver of the overlapping mutations. All four antigenic-drift mutations are located at the surface of the NA globular head, opposite the tetramer interface and viral membrane (Supplementary Fig. 1), potentially allowing interaction to both antibody and substrate. Our screening did not find the G249K substitution able to affect virus growth sufficiently to alter plaque size, but a small effect on enzyme affinity is possible. Thus, selection of antigenic-drift NA mutations probably inadvertently provided a permissive context for the H275Y mutation and altered its phenotypic outcome. The antigenic drift-driven NA mutation spread can be a plausible explanation in addition to previously proposed genetic hitchhiking process ${ }^{36}$. The non-overlapping mutation V234M, not located at the NA surface, did not affect enzyme affinity and was not a probable antigenic-drift mutation. However, it preceded a series of NA affinity-changing and antigenic-drift mutations, showing that the first altered NA phenotype was expression level and the second was functionality, suggesting that protein expression level could affect introduction of function-changing mutations during protein evolution.

Our mechanistic reconstruction of the evolutionary course of the $\mathrm{H} 1 \mathrm{~N} 1$ viruses has direct implications for assessing the potential fitness, evolution and spread of other H275Y-mutant viruses of N1 subtype. In the case of 2009 pdmH1N1 viruses, the severe defects on NA functionality generated by the H275Y mutation is consistent with the reduced transmissibility of $\mathrm{H} 275 \mathrm{Y}$ mutants experimentally ${ }^{37,38}$ and the limited detection of such viruses during surveillance $(1 \% \sim 3.5 \% \text { detection rate })^{39-41}$. However, experimental transmission and community spread of H275Y-mutant pdmH1N1 viruses has been reported ${ }^{40,42-44}$, including a very recent alarming community spread in Sapporo, $\operatorname{Japan}^{45}$, suggesting that potential permissive mutation might have been emerged in certain cluster of variants. Three studies using computational predictions or in vitro and in vivo experiments have suggested several potential permissive NA mutations for the $\mathrm{H} 275 \mathrm{Y}$ in pdmH1N1 viruses ${ }^{46-48}$, which are entirely different from the one identified in seasonal H1N1 viruses. Given that NA genes of the seasonal $\mathrm{H} 1 \mathrm{~N} 1$ and pdmH1N1 were phylogenetically distant and had extensive amino acid dissimilarities, it is not surprising that different $\mathrm{H} 275 \mathrm{Y}$-permissive mutations would be required for pdmH1N1 viruses, which is also very likely to be the case for other N1subtype viruses. Our study suggest that the evolution course of pdmH1N1 NA towards the potential resistance spread should be monitored longitudinally by assessing the extent of $\mathrm{H} 275 \mathrm{Y}$ generated NA defects, especially in community-transmitted resistant isolates. The NA defects evaluated by a spectrum of assays from protein expression, enzyme activity to virus transmission level would be most informative for assessing dominance potential of resistant viruses. The occurrence of smaller or no NA defects in all assay levels is worth a high alert.

Similarly, the deleterious outcome of the H275Y mutation on the NA protein from $\mathrm{H} 5 \mathrm{~N} 1$ viruses is consistent with the rare case of resistant viruses detected in the field (only three cases where drug treatment or prophylaxis was used $)^{49,50}$. As the highly pathogenic $\mathrm{H} 5 \mathrm{~N} 1$ (hpH5N1) viruses carry unique virulence determinants $^{51}$, H275Y-generated NA defects may not alter their overall pathogenicity. However, as hpH5N1 infection is a substantial public health concern, it would be advisable to compare the biological fitness of wild-type versus emerging 
resistant viruses by identifying $\mathrm{H} 275 \mathrm{Y}$-generated NA defects. Of special value in our study is the use of NA-containing plasmids to assess defects in NA protein expression and activity, as described here, averting the need to engineer infectious $\mathrm{hpH} 5 \mathrm{~N} 1$ virus.

Our findings of the $\mathrm{H} 275 \mathrm{Y}$ mutation in $\mathrm{H} 1 \mathrm{~N} 1$ viruses may help in assessing the biological outcome of other NA inhibitorresistance markers. NA inhibitor-resistance mutations are virus subtype- and drug-dependent and may be NA catalytic residues (such as NA 118, 276, 292 and so on, and N2 numbering) or framework residues (such as NA 119, 222, 274, 294 and so on, and N2 numbering $)^{7,52}$. The H275Y (274 in N2 numbering) is a framework residue mutation ${ }^{52}$. To date, surveillance and clinical observation have shown that R292K, E119V, N294S and I222V mutant $\mathrm{H} 3 \mathrm{~N} 2$ viruses $^{4,7-9}, \mathrm{I} 222 \mathrm{~V}$ and I222R mutant pandemic $\mathrm{H} 1 \mathrm{~N} 1$ viruses ${ }^{40,53,54}$, and R292K mutant H7N9 viruses 55 have emerged only from drug-treated individuals and have not been able to spread at the population level. Their compromised epidemiologic fitness indicates that the biological outcome of these mutations on the proteins and viruses remains detrimental. Among these, resistance mutations at the catalytic residues presumably would cause much more profound loss of NA functionality than framework mutations, and could consequently completely eliminate the virus biological fitness. However, the smaller loss-of-function by framework mutation might be restored more readily, such as the $\mathrm{H} 275 \mathrm{Y}$. Another two framework mutations I222V and I222R in the pandemic H1N1 viruses have shown less loss of NA function ${ }^{56,57}$, and its NA evolution course may therefore merit more attention.

Interaction of the $\mathrm{H} 275 \mathrm{Y}$ mutation with permissive and compensatory NA mutations explains the restoration of the NA function and the fitness of the resistant viruses to the wild-type level, but NA function alone does not explain why the resistant viruses outtransmitted over the wild-type viruses. Therefore, the roles of other viral proteins in conferring the greater fitness of resistant viruses should be examined. For example, HA binding to receptors also plays important role in influenza virus transmission. The NA and HA genes of H1N1 viruses showed the same genetic clustering and antigenic lineage patterns ${ }^{16-19}$, indicating their co-evolution. The HAs of the resistant viruses exhibited reduced reactivity to antibody inhibition ${ }^{58}$. HA mutations can promote replication of BR07-like H275Y-mutant viruses in cells ${ }^{59}$ and drive NA mutations that alter antigenicity and NA-inhibitor susceptibility ${ }^{60}$. All of these findings suggest the occurrence of phenotypic interactions between the HA and NA proteins (probably to promote functional balance) during the evolution of H275Y-mutant viruses. Comparison of the HA sequences of the BR07-like viruses used in the ferret experiment revealed four HA mutations (G185V, N186D, A189T and H192R) shared by the H275Y-mutant viruses (Supplementary Table 5). These four positions are located in or near to the 190 helix, which is one of the three structure elements enclosing the base of the HA binding site $^{61}$; although these positions are not directly involved in receptor binding, whether and how they can affect the receptor binding and virus transmissibility would be of interest for further study. In addition, intra-subtype, inter-clade segment reassortment events observed in the BR07-like resistant viruses $^{18,62}$ suggest that a combination of internal protein interactions plays a role in enhancing overall virus fitness.

In conclusion, we have shown how the fitness cost of a drugresistant NA mutation in human seasonal influenza virus can be reduced or eliminated during NA evolution, allowing the resistant strain to spread. As influenza viruses continue to evolve under immune pressure and NA inhibitors remain the primary therapeutic option, we suggest that NA genetics, antigenic drift and resistance mutation-generated NA functional outcome should be collectively and continually monitored to assess the biologic fitness of emerging resistant viruses and their potential evolutionary course towards resistance spread.

\section{Methods}

Cells and viruses. Pandemic DM/524/09 and DM/528/09 viruses were provided by Statens Serum Institute, Copenhagen, Denmark. NY/3467/09 and NY/1692/09 viruses were provided by the Wadsworth Center of the New York State Department of Health. Wild-type and NA H275Y-mutant MS/03/02 viruses were provided by the Neuraminidase Inhibitor Susceptibility Network. The remaining $\mathrm{H} 1 \mathrm{~N} 1$ viruses, including CA/04/09, BR/59/07, HW/28/07, NJ/15/07, GA/17/06, $\mathrm{GA} / 20 / 06, \mathrm{TX} / 30 / 07$ and MEM/13/06, were provided by the US Centers for Disease Control and Prevention. The NA gene segments of VN/1203/04 and HK/213/ $03 \mathrm{H} 5 \mathrm{~N} 1$ viruses were generated into plasmids previously ${ }^{63,64}$, and no infectious $\mathrm{H} 5 \mathrm{~N} 1$ viruses were used in the present study. All virus stocks used underwent an initial limited number $(1 \sim 2)$ of passages in MDCK cells on reception, to maintain their original properties. The $50 \%$ tissue culture infectious dose $\left(\right.$ TCID $\left._{50}\right)$ or plaque forming unit was used to measure virus infectivity in MDCK cells as previously described $^{37}$.

Sequence analysis. Viral RNA was isolated by using the RNeasy Mini kit (Qiagen). Samples were reverse-transcribed and analysed by PCR, using segmentspecific primers as described previously ${ }^{65}$. Sequencing was performed by the Hartwell Center for Bioinformatics and Biotechnology at St Jude Children's Research Hospital. DNA sequences were completed and edited by using the Lasergene software package (DNASTAR).

Phylogenetic estimation of timing and sequence of mutations. All the published NA gene sequences of seasonal H1N1 viruses were downloaded from NCBI (Influenza Virus Resource). Initial visual inspection of multiple NA sequence alignments containing taxa with and without the $\mathrm{H} 275 \mathrm{Y}$ oseltamivir resistance mutation identified 11 amino acid mutations associated with the NA lineage divergence. To estimate the time of most recent common ancestor that possessed the mutations of interest, we used all available full-length H1N1 NA sequences that also had the exact date of isolation in the accession, and generated three data sets comprising randomly selected taxa plus the past vaccine strains, reference sequences and six available pre-2007/2008 H275Y variants (ntax $=413$ for each data set). The SRD06 approximate codon model of evolution with an HKY85 + gamma nucleotide substitution model for codon position $1+2$ and codon partition 3 was used to estimate the phylogenetic tree. The ancestral state reconstruction of all tested mutations was jointly estimated with the phylogeny. The NA evolutionary history and the ancestral states reconstruction were estimated using a tip date calibrated Bayesian relaxed-clock phylogenetic tree reconstruction method ${ }^{27}$. We assigned the individual mutations as a tip observed state ${ }^{66}$. These mutations were indicators for possible adaptive mutations. We assessed which mutations were fixed in the population, the sequence of fixation and when this fixation occurred. Phylogenetic analysis was carried out in BEAST (v1.7.3).

Plasmid construction and site-directed mutagenesis. The full-length complementary DNA (eight segments) of BR/59/07 virus and the NA segments of GA/ $17 / 06$ and GA/20/06 viruses were cloned into the pHW2000 plasmid vector to generate rg viruses, as described previously ${ }^{67}$. Mutations of interest were introduced into the corresponding NA genes by using QuickChange site-directed mutagenesis (Stratagene) and confirmed by Sanger sequencing. The full-length protein-coding sequences of the NA genes of interest were cloned into the pCAGGS plasmid vector for expression of recombinant NA proteins in BHK cells, as described previously ${ }^{68}$. The HA epitope tag (YPYDVPDYA) was added to the $\mathrm{N}$ or $\mathrm{C}$ terminus of the NA protein by incorporating the coding sequences into the primers.

Generation of $\mathbf{r g}$ influenza viruses. Reverse-genetics viruses were rescued by transfecting a 293T/MDCK cell co-culture with eight PHW2000 plasmids containing the eight virus segments, using TransIT LT-1 (Panvera), as described previously ${ }^{67}$. Rescued viruses contained variant NA segments in the uniform backbone from other seven segments of the BR/59/07 virus. The rescued supernatants from co-culture were first titrated by plaque assay and then one passage of the supernatant in MDCK cells (multiplicity of infection $=0.001 \sim 0.01$ ) was used to prepare stocks of all rg viruses.

Generation and detection of recombinant NA proteins. BHK cells were transfected with the respective NA gene-containing pCAGSS plasmids by using Lipofectamine 2000 (Invitrogen), as described previously ${ }^{68}$, and NA protein expression was measured by NA enzyme activity assay, western blotting or flow cytometry. For comparison of different proteins, BHK cells were transfected with equal quantities of the respective pCAGGS plasmids $(0.5 \mu \mathrm{g}$ unless indicated otherwise) in a 12 -well plate, in parallel. For western blotting, $0.05 \mu \mathrm{g}$ of pCMV-GFP plasmid was cotransfected with the respective pCAGGS plasmid. Cells were harvested in $\sim 36 \mathrm{~h}$ post transfection. For the subsequent NA enzyme activity assay, cells were lysed 
with non-denaturing NA enzyme buffer containing $0.5 \%$ Triton X-100. For western blotting, cells were lysed with denaturing SDS-containing RIPA buffer. All samples were processed in parallel. For protein expression level determination, anti-HA epitope monoclonal antibodies (Sigma, 1:20,000) were used to detect the epitope-tagged recombinant proteins in western blotting or flow cytometry. In western blotting, $\beta$-actin was detected (anti- $\beta$-actin, Santa Cruz, 1:20,000) as loading control and green fluorescent protein (GFP, detected by anti-GFP, Santa Cruz, 1:2,000) was used as transfection efficiency control. Fluorescent dye-labelled (IRDye680 or IRDye800) anti-mouse or -rabbit secondary antibodies (LI-COR, 1:20,000) were used to detect the respective primary antibodies. The blot signals were visualized and analysed in Odyssey imaging system (LI-COR). Full-gel images of the blots used in the Figures are provided in Supplementary Fig. 9.

NA enzyme activity and kinetics. The NA activity assay was based on a fluorometric assay using the substrate $2^{\prime}$-(4-methylumbelliferyl)- $\alpha$-D-N-acetylneuraminic acid (MUNANA) (Sigma-Aldrich) in enzyme buffer containing $33 \mathrm{mM}$ 2- (N-morpholino) ethanesulphonic acid hydrate (Sigma-Aldrich), $4 \mathrm{mM}$ $\mathrm{CaCl}_{2}$ at $\mathrm{pH} 6.5$ at $37^{\circ} \mathrm{C}$ for $30 \mathrm{~min}^{69}$. Hydrolysis of 1 mol MUNANA by NA liberated 1 mol fluorescent product 4-methylumbelliferone ${ }^{69}$ and the fluorescence of liberated product was read in a Synergy 2 multi-mode microplate reader (BioTek), using excitation and emission wavelengths of 360 and $460 \mathrm{~nm}$, respectively. Purified 4-methylumbelliferone (Sigma-Aldrich) was used as a standard for estimation of product generation and substrate consumption in the assay (for example, Supplementary Fig. 8a). For NA enzymatic activity measurement, all the harvested samples were serially diluted and were assayed in parallel with $100 \mu \mathrm{M}$ MUNANA, and then NA quantity-activity curves were generated. The dilution at which all NAs were within their linear range of product generation and approximately consumed $<20 \%$ of substrate was adopted for activity measurement (for example, Supplementary Fig. 8b,c). Next, the activity was normalized to a reference NA as the \% relative activity (for example, Fig. 2a). The enzyme activity of all expressed NA proteins was measured by the same process.

For NA kinetics assay, all viruses were standardized to a dose of $10^{6} \mathrm{PFU} \mathrm{ml}^{-1}$, a dose at which all viruses were determined to consume $<10 \%$ of $100 \mu \mathrm{M}$ MUNANA substrate in NA activity assays (for example, Supplementary Fig. 8a). We then measured NA enzyme kinetics in the enzyme buffer using serial concentrations of MUNANA (final concentration, 800-6.25 $\mu \mathrm{M}$, twofold serial dilution) in a total volume of $50 \mu \mathrm{l}$. The fluorescence of released 4methylumbelliferone was measured at $37^{\circ} \mathrm{C}$ every $60 \mathrm{~s}$ for $40 \mathrm{~min}$. Km was calculated by fitting the data to the Michaelis-Menten equations by nonlinear regression in Prism5 software (GraphPad).

Transmission experiments in ferrets. All experiments were conducted in an ABSL2 + laboratory under applicable laws and guidelines, and after approval from the St Jude Children's Research Hospital Animal Care and Use Committee. Fourto 5-month-old ferrets were obtained from Triple F farm; all were tested seronegative for contemporary influenza A H1N1 and H3N2 viruses and influenza B viruses. Ferrets were initially housed in isolators and monitored for 3-5 days to establish baseline body temperature and overall health. Donor and contact ferrets were housed separately. Transmission experiments $(1$ donor +1 direct-contact recipient +1 respiratory-droplet recipient) were conducted in triplicate for each virus. Three donor ferrets were inoculated intranasally with $10^{5} \mathrm{TCID}_{50}$ of virus in $1.0-\mathrm{ml}$ sterile PBS. At day 1 p.i., each donor was co-housed with one naive directcontact ferret. One additional naive ferret was placed in an adjacent cage separated by double-layered ( $\sim 5 \mathrm{~cm}$ apart) perforated dividers to assess respiratory-droplet transmission; air flow was directed from the donor cage toward the recipient cage using a Borazine gun (Zero Toys). Nasal wash samples were collected at days 1 and 2 p.i, and then every other day for 14 days by flushing both nostrils with $1.0 \mathrm{ml}$ PBS. TCID 50 titres of nasal washes were determined in MDCK cells. Serum samples were collected 3 weeks after inoculation, treated with receptor-destroying enzyme, heat-inactivated at $56^{\circ} \mathrm{C}$ for $30 \mathrm{~min}$ and tested against the homologous virus by $\mathrm{HI}$ assay with $0.5 \%$ packed turkey red blood cells.

Statistical analysis. All statistical analyses were performed using Student's $t$-test in Prism5 software. Data are presented as mean \pm s.e.m. The level of significance was determined as $P<0.05$.

\section{References}

1. Nelson, M. I. \& Holmes, E. C. The evolution of epidemic influenza. Nat. Rev. Genet. 8, 196-205 (2007).

2. Domingo, E. \& Holland, J. J. RNA virus mutations and fitness for survival. Annu. Rev. Microbiol. 51, 151-178 (1997).

3. Wargo, A. R. \& Kurath, G. Viral fitness: definitions, measurement, and current insights. Curr. Opin. Virol. 2, 538-545 (2012).

4. Kiso, M. et al. Resistant influenza A viruses in children treated with oseltamivir: descriptive study. Lancet 364, 759-765 (2004).
5. Gubareva, L. V., Kaiser, L., Matrosovich, M. N., Soo-Hoo, Y. \& Hayden, F. G. Selection of influenza virus mutants in experimentally infected volunteers treated with oseltamivir. J. Infect. Dis. 183, 523-531 (2001).

6. Ward, P., Small, I., Smith, J., Suter, P. \& Dutkowski, R. Oseltamivir (Tamiflu) and its potential for use in the event of an influenza pandemic. J. Antimicrob. Chemother. 55(Suppl 1): i5-i21 (2005).

7. Lackenby, A., Thompson, C. I. \& Democratis, J. The potential impact of neuraminidase inhibitor resistant influenza. Curr. Opin. Infect. Dis. 21, 626-638 (2008).

8. Sheu, T. G. et al. Surveillance for neuraminidase inhibitor resistance among human influenza A and B viruses circulating worldwide from 2004 to 2008. Antimicrob. Agents Chemother. 52, 3284-3292 (2008).

9. Monto, A. S. et al. Detection of influenza viruses resistant to neuraminidase inhibitors in global surveillance during the first 3 years of their use. Antimicrob. Agents Chemother. 50, 2395-2402 (2006).

10. Dharan, N. J. et al. Infections with oseltamivir-resistant influenza $\mathrm{A}(\mathrm{H} 1 \mathrm{~N} 1)$ virus in the United States. JAMA 301, 1034-1041 (2009).

11. Hurt, A. C. et al. Emergence and spread of oseltamivir-resistant A(H1N1) influenza viruses in Oceania, South East Asia and South Africa. Antiviral Res. 83, 90-93 (2009).

12. Meijer, A. et al. Oseltamivir-resistant influenza virus A (H1N1), Europe, 2007-08 season. Emerg. Infect. Dis. 15, 552-560 (2009).

13. Moscona, A. Global transmission of oseltamivir-resistant influenza. New Engl. J. Med. 360, 953-956 (2009).

14. Weinstock, D. M. \& Zuccotti, G. The evolution of influenza resistance and treatment. JAMA 301, 1066-1069 (2009).

15. Rameix-Welti, M. A., Enouf, V., Cuvelier, F., Jeannin, P. \& van der, W. S. Enzymatic properties of the neuraminidase of seasonal H1N1 influenza viruses provide insights for the emergence of natural resistance to oseltamivir. PLoS Pathog. 4, e1000103 (2008).

16. Collins, P. J. et al. Structural basis for oseltamivir resistance of influenza viruses. Vaccine 27, 6317-6323 (2009).

17. Eshaghi, A. et al. Genetic microheterogeneity of emerging $\mathrm{H} 275 \mathrm{Y}$ influenza virus A (H1N1) in Toronto, Ontario, Canada from the 2007-2008 respiratory season. J. Clin. Virol. 45, 142-145 (2009).

18. Zaraket, H. et al. Genetic makeup of amantadine-resistant and oseltamivirresistant human influenza A/H1N1 viruses. J. Clin. Microbiol. 48, 1085-1092 (2010).

19. Casalegno, J. S. et al. Oseltamivir-resistant influenza A(H1N1) viruses in south of France, 2007/2009. Antiviral Res. 87, 242-248 (2010).

20. Ives, J. A. et al. The H274Y mutation in the influenza A/H1N1 neuraminidase active site following oseltamivir phosphate treatment leave virus severely compromised both in vitro and in vivo. Antiviral Res. 55, 307-317 (2002).

21. Abed, Y., Goyette, N. \& Boivin, G. A reverse genetics study of resistance to neuraminidase inhibitors in an influenza A/H1N1 virus. Antivir. Ther. 9, 577-581 (2004).

22. Herlocher, M. L. et al. Influenza viruses resistant to the antiviral drug oseltamivir: transmission studies in ferrets. J. Infect. Dis. 190, 1627-1630 (2004).

23. Baz, M., Abed, Y., Simon, P., Hamelin, M. E. \& Boivin, G. Effect of the neuraminidase mutation $\mathrm{H} 274 \mathrm{Y}$ conferring resistance to oseltamivir on the replicative capacity and virulence of old and recent human influenza $\mathrm{A}(\mathrm{H} 1 \mathrm{~N} 1)$ viruses. J. Infect. Dis. 201, 740-745 (2010).

24. Bloom, J. D., Gong, L. I. \& Baltimore, D. Permissive secondary mutations enable the evolution of influenza oseltamivir resistance. Science 328, 1272-1275 (2010).

25. Rameix-Welti, M. A. et al. Neuraminidase of 2007-2008 influenza A(H1N1) viruses shows increased affinity for sialic acids due to the D344N substitution Antivir. Ther. 16, 597-603 (2011).

26. Abed, Y., Pizzorno, A., Bouhy, X. \& Boivin, G. Role of permissive neuraminidase mutations in influenza A/Brisbane/59/2007-like (H1N1) viruses. PLoS Pathog. 7, e1002431 (2011).

27. Drummond, A. J., Ho, S. Y., Phillips, M. J. \& Rambaut, A. Relaxed phylogenetics and dating with confidence. PLoS Biol. 4, e88 (2006)

28. Wong, D. D. et al. Comparable fitness and transmissibility between oseltamivirresistant pandemic 2009 and seasonal H1N1 influenza viruses with the $\mathrm{H} 275 \mathrm{Y}$ neuraminidase mutation. J. Virol. 86, 10558-10570 (2012).

29. Bouvier, N. M., Rahmat, S. \& Pica, N. Enhanced mammalian transmissibility of seasonal influenza $\mathrm{A} / \mathrm{H} 1 \mathrm{~N} 1$ viruses encoding an oseltamivir-resistant neuraminidase. J. Virol. 86, 7268-7279 (2012).

30. Lehner, B. Molecular mechanisms of epistasis within and between genes. Trends Genet. 27, 323-331 (2011).

31. Kryazhimskiy, S., Dushoff, J., Bazykin, G. A. \& Plotkin, J. B. Prevalence of epistasis in the evolution of influenza A surface proteins. PLoS Genet. 7, e1001301 (2011).

32. Rambaut, A. et al. The genomic and epidemiological dynamics of human influenza A virus. Nature 453, 615-619 (2008). 
33. Shapiro, B., Rambaut, A., Pybus, O. G. \& Holmes, E. C. A phylogenetic method for detecting positive epistasis in gene sequences and its application to RNA virus evolution. Mol. Biol. Evol. 23, 1724-1730 (2006).

34. Gong, L. I., Suchard, M. A. \& Bloom, J. D. Stability-mediated epistasis constrains the evolution of an influenza protein. Elife 2, e00631 (2013).

35. Sandbulte, M. R. et al. Discordant antigenic drift of neuraminidase and hemagglutinin in $\mathrm{H} 1 \mathrm{~N} 1$ and $\mathrm{H} 3 \mathrm{~N} 2$ influenza viruses. Proc. Natl Acad. Sci. USA 108, 20748-20753 (2011).

36. Holmes, E. C. Virology. Helping the resistance. Science 328, 1243-1244 (2010).

37. Duan, S. et al. Oseltamivir-resistant pandemic H1N1/2009 influenza virus possesses lower transmissibility and fitness in ferrets. PLoS Pathog. 6, e1001022 (2010).

38. Hamelin, M. E. et al. Reduced airborne transmission of oseltamivir-resistant pandemic A/H1N1 virus in ferrets. Antivir. Ther. 16, 775-779 (2011).

39. Gubareva, L. V. et al. Comprehensive assessment of 2009 pandemic influenza A (H1N1) virus drug susceptibility in vitro. Antivir. Ther. 15, 1151-1159 (2010).

40. Hurt, A. C. et al. Antiviral resistance during the 2009 influenza A H1N1 pandemic: public health, laboratory, and clinical perspectives. Lancet Infect. Dis. 12, 240-248 (2012).

41. Ujike, M. et al. Monitoring and characterization of oseltamivir-resistant pandemic (H1N1) 2009 virus, Japan, 2009-2010. Emerg. Infect. Dis. 17, 470-479 (2011).

42. Hurt, A. C. et al. Community transmission of oseltamivir-resistant A(H1N1)pdm09 influenza. New Engl. J. Med. 365, 2541-2542 (2011).

43. Kiso, M. et al. Characterization of oseltamivir-resistant $2009 \mathrm{H} 1 \mathrm{~N} 1$ pandemic influenza A viruses. PLoS Pathog. 6, e1001079 (2010).

44. Seibert, C. W. et al. Oseltamivir-resistant variants of the 2009 pandemic H1N1 influenza A virus are not attenuated in the guinea pig and ferret transmission models. J. Virol. 84, 11219-11226 (2010).

45. Takashita, E. et al. A community cluster of influenza A(H1N1)pdm09 virus exhibiting cross-resistance to oseltamivir and peramivir in Japan, November to December 2013. Euro. Surveill 19 pii 20666 (2014).

46. Wu, N. C. et al. Systematic identification of H274Y compensatory mutations in influenza A virus neuraminidase by high-throughput screening. J. Virol. 87, 1193-1199 (2013).

47. Abed, Y., Pizzorno, A., Bouhy, X., Rheaume, C. \& Boivin, G. Impact of potential permissive neuraminidase mutations on viral fitness of the $\mathrm{H} 275 \mathrm{Y}$ oseltamivirresistant influenza $\mathrm{A}(\mathrm{H} 1 \mathrm{~N} 1) \mathrm{pdm} 09$ virus in vitro, in mice and in ferrets. J. Virol. 88, 1652-1658 (2014).

48. Bloom, J. D., Nayak, J. S. \& Baltimore, D. A computational-experimental approach identifies mutations that enhance surface expression of an oseltamivir-resistant influenza neuraminidase. PLOS ONE 6, e22201 (2011).

49. Le, Q. M. et al. Avian flu: isolation of drug-resistant H5N1 virus. Nature 437, 1108 (2005).

50. de Jong, M. D. et al. Oseltamivir resistance during treatment of influenza A (H5N1) infection. New Engl. J. Med. 353, 2667-2672 (2005).

51. Salomon, R. \& Webster, R. G. The influenza virus enigma. Cell 136, 402-410 (2009).

52. Das, K., Aramini, J. M., Ma, L. C., Krug, R. M. \& Arnold, E. Structures of influenza A proteins and insights into antiviral drug targets. Nat. Struct. Mol. Biol. 17, 530-538 (2010).

53. Centers for Disease Control and Prevention (CDC). Oseltamivir-resistant 2009 pandemic influenza $A(\mathrm{H} 1 \mathrm{~N} 1)$ virus infection in two summer campers receiving prophylaxis--North Carolina, 2009. Morb. Mortal. Wkly Rep. 58, 969-972 (2009).

54. Nguyen, H. T., Fry, A. M., Loveless, P. A., Klimov, A. I. \& Gubareva, L. V. Recovery of a multidrug-resistant strain of pandemic influenza A 2009 (H1N1) virus carrying a dual $\mathrm{H} 275 \mathrm{Y} / \mathrm{I} 223 \mathrm{R}$ mutation from a child after prolonged treatment with oseltamivir. Clin. Infect. Dis. 51, 983-984 (2010).

55 . $\mathrm{Hu}, \mathrm{Y}$. et al. Association between adverse clinical outcome in human disease caused by novel influenza A H7N9 virus and sustained viral shedding and emergence of antiviral resistance. Lancet 381, 2273-2279 (2013).

56. Pizzorno, A., Bouhy, X., Abed, Y. \& Boivin, G. Generation and characterization of recombinant pandemic influenza $\mathrm{A}(\mathrm{H} 1 \mathrm{~N} 1)$ viruses resistant to neuraminidase inhibitors. J. Infect. Dis. 203, 25-31 (2011).

57. Pizzorno, A. et al. Impact of mutations at residue i 223 of the neuraminidase protein on the resistance profile, replication level, and virulence of the 2009 pandemic influenza virus. Antimicrob. Agents Chemother. 56, 1208-1214 (2012).

58. Wu, W. L. et al. The 2008-2009 H1N1 influenza virus exhibits reduced susceptibility to antibody inhibition: Implications for the prevalence of oseltamivir resistant variant viruses. Antiviral Res. 93, 144-153 (2012).
59. Ginting, T. E. et al. Amino acid changes in hemagglutinin contribute to the replication of oseltamivir-resistant $\mathrm{H} 1 \mathrm{~N} 1$ influenza viruses. J. Virol. 86, 121-127 (2012).

60. Hensley, S. E. et al. Influenza A virus hemagglutinin antibody escape promotes neuraminidase antigenic variation and drug resistance. PLoS ONE 6, e15190 (2011).

61. Gamblin, S. J. \& Skehel, J. J. Influenza hemagglutinin and neuraminidase membrane glycoproteins. J. Biol. Chem. 285, 28403-28409 (2010).

62. Yang, J. R. et al. Reassortment and mutations associated with emergence and spread of oseltamivir-resistant seasonal influenza A/H1N1 viruses in 20052009. PLoS ONE 6, e18177 (2011).

63. Yen, H. L. et al. Neuraminidase inhibitor-resistant recombinant A/Vietnam/ 1203/04 (H5N1) influenza viruses retain their replication efficiency and pathogenicity in vitro and in vivo. J. Virol. 81, 12418-12426 (2007).

64. Yen, H. L. et al. Changes in $\mathrm{H} 5 \mathrm{~N} 1$ influenza virus hemagglutinin receptor binding domain affect systemic spread. Proc. Natl Acad. Sci. USA 106, 286-291 (2009).

65. Hoffmann, E., Stech, J., Guan, Y., Webster, R. G. \& Perez, D. R. Universal primer set for the full-length amplification of all influenza A viruses. Arch. Virol. 146, 2275-2289 (2001).

66. Lemey, P., Rambaut, A., Drummond, A. J. \& Suchard, M. A. Bayesian phylogeography finds its roots. PLoS Comput. Biol. 5, e1000520 (2009).

67. Hoffmann, E., Neumann, G., Kawaoka, Y., Hobom, G. \& Webster, R. G. A DNA transfection system for generation of influenza A virus from eight plasmids. Proc. Natl Acad. Sci. USA 97, 6108-6113 (2000).

68. Reed, M. L. et al. The $\mathrm{pH}$ of activation of the hemagglutinin protein regulates H5N1 influenza virus pathogenicity and transmissibility in ducks. J. Virol. 84, 1527-1535 (2010).

69. Potier, M., Mameli, L., Belisle, M., Dallaire, L. \& Melancon, S. B. Fluorometric assay of neuraminidase with a sodium (4-methylumbelliferyl-alpha-D-Nacetylneuraminate) substrate. Anal. Biochem. 94, 287-296 (1979).

\section{Acknowledgements}

This work was supported by Contract Number HHSN266200700005C from the National Institute of Allergy and Infectious Disease, US National Institutes of Health and by the American Lebanese Syrian Associated Charities (ALSAC). We thank Sharon Naron for editing the manuscript, Drs Nancy Cox (U.S. Centers for Disease Control and Prevention) and Kristen St George (New York State Department of Health) for providing the seasonal H1N1 viruses, and Dr Charlie Russell for providing the pCAGGS plasmid and BHK cells. We thank Petr Krylov, Erik Karlsson, Heather Forrest, John Franks, Lisa Kercher, David S. Carey and Betsy Little for assistance in the ABSL2 + laboratory. We thank Dr Suzanne Jackowski for helpful discussion and advice.

\section{Author contributions}

D.S. designed and conducted all experiments and wrote the manuscript. E.A.G. oversaw the experiments. J.B. performed the statistical phylogenetic analysis. Z.H. contributed to molecular and animal experiments. B.T. and S.P. contributed to animal experiments. P.K. contributed to cellular and animal experiments. R.G.W. and R.J.W. provided conceptual direction, designed and supervised the overall study and revised the manuscript. All authors commented and revised the manuscript.

\section{Additional information}

Accession codes: The full genome sequence of A/Brisbane/59/2007(H1N1) virus has been deposited in Genebank database under the accession codes CY058484 to CY058491.

Supplementary Information accompanies this paper at http://www.nature.com/ naturecommunications

Competing financial interests: Although this study had no corporate funding, R.G.W and E.A.G. are currently performing a different research study funded by F. HoffmannLaRoche, Ltd., Basel, Switzerland. The remaining authors declare no competing financial interests.

Reprints and permission information is available online at http://npg.nature.com/ reprintsandpermissions/

How to cite this article: Duan, S. et al. Epistatic interactions between neuraminidase mutations facilitated the emergence of the oseltamivir-resistant H1N1 influenza viruses Nat. Commun. 5:5029 doi: 10.1038/ncomms6029 (2014). 